\title{
Ability of a global three-dimensional model to locate regional events
}

\author{
M. H. Ritzwoller, N. M. Shapiro, A. L. Levshin, E. A. Bergman, and E. R. Engdahl \\ Center for Imaging the Earth's Interior, Department of Physics, University of Colorado at Boulder, Boulder, Colorado, USA
}

Received 22 August 2002; revised 31 March 2003; accepted 29 April 2003; published 30 July 2003.

[1] We assess the ability of a global three-dimensional (3D) seismic model of the crust and upper mantle (CUB2.0) to locate seismic events using regional travel time data alone (epicentral distances $<20^{\circ}$ ). Assessments are based on a "ground truth" (GT) database, comprising nearly 1000 uncommonly well-located events which occur in 23 event clusters across Eurasia and North Africa, groomed $P$ and $P_{n}$ arrival time data observed at regional distances from individual events, and $\sim 1000$ empirical phase path anomalies produced from event clusters. Evidence is presented that supports the conversion of the shear velocities $\left(v_{s}\right)$ in CUB2.0 to compressional velocities $\left(v_{p}\right)$ in the upper mantle using the thermoelastic properties of an assumed mantle composition rather than traditional empirical scaling relationships. Two principal results are presented. First, this $3 \mathrm{D} v_{p}$ model fits the empirical $P$ and $P_{n}$ phase path anomalies very well in both pattern and absolute level. Second, location assessments demonstrate that intrinsic regional location accuracy is $\sim 5 \mathrm{~km}$ using the 3D $v_{p}$ model and $\sim 10 \mathrm{~km}$ using the 1D model AK135. These findings highlight the importance of GT databases in assessing regional travel time models and establish that a global 3D $v_{s}$ model, together with $v_{p}$ inferred from it, provides a solid basis on which to build improvements in regional location capabilities. INDEX TERMS: 7218 Seismology: Lithosphere and upper mantle; 7203 Seismology: Body wave propagation; 7219 Seismology: Nuclear explosion seismology; 7230 Seismology: Seismicity and seismotectonics; KEYWORDS: seismic locations, tomography, mantle, crust, surface waves

Citation: Ritzwoller, M. H., N. M. Shapiro, A. L. Levshin, E. A. Bergman, and E. R. Engdahl, Ability of a global three-dimensional model to locate regional events, J. Geophys. Res., 108(B7), 2353, doi:10.1029/2002JB002167, 2003.

\section{Introduction}

[2] The seismic location inverse problem has a history dating back almost a century, at least to Geiger [1912]. There has been a recent resurgence of interest in improving the ability to estimate reliable seismic locations for both earthquakes and explosions [e.g., Thurber and Rabinowitz, 2000]. One reason for this resurgence is the desire to apply advances in seismological models and practice to improve event locations in global catalogs produced, for example, by the International Seismological Centre (ISC), the U.S. National Earthquake Information Service (NEIS), or the International Data Center (IDC). Another reason is that the Comprehensive Nuclear Test-Ban Treaty (CTBT), irrespective of its current status, has motivated greater emphasis on locating small natural or human-produced seismic events. The CTBT specifies a location uncertainty of $1000 \mathrm{~km}^{2}$ or less for events with magnitudes greater than or equal to 4.0 [e.g., Ringdal and Kennett, 2001]. In addition, there has been growing recognition of the importance of high-quality locations in seismic tomography and fault zone characterization.

[3] Efforts to improve the location of seismic events have fallen into two broad categories: advances in seismic travel

Copyright 2003 by the American Geophysical Union. 0148-0227/03/2002JB002167\$09.00 time models to improve absolute locations and innovations in location methods, in particular, using multiple event location methods to improve relative location capabilities [e.g., Poupinet et al., 1984; Frémont and Malone, 1987; Pavlis, 1992; Got et al., 1994; Waldhauser and Ellsworth, 2000]. These categories are not mutually exclusive, and each possesses characteristic strengths and limitations. The emphasis of this paper will be on testing a specific type of travel time model, in which regional seismic phases are computed from a global three-dimensional (3D) seismic model. The keywords here are "regional" and "global 3D seismic model," which we describe further below.

[4] The phrase "regional" refers to epicentral distances less than $\sim 20^{\circ}$, in contrast with teleseismic distances. At present, regional seismic phases remain relatively poorly studied and modeled except in regions of the world that are heavily populated, seismically active, and well instrumented (e.g., the western U.S., Japan, parts of Europe, parts of China, etc.). Regional data, therefore, are typically weighted down strongly in location procedures that mix regional and teleseismic phases. In particular, the need for consistency in global catalogs has inhibited the adoption of modern seismic models in the major global seismic catalogs. For example, the ISC and the NEIS continue to use the Jeffreys-Bullen travel-time tables [Jeffreys and Bullen, 1940], and the IDC uses travel times from the 1D model 
IASP91 [Kennett and Engdahl, 1991], neither of which is designed to fit regional travel times nor identify regional phases. Substantial improvements in global seismicity catalogs would derive through better use of regional data, which would be made possible by better travel time models. In addition, the concentration of monitoring efforts stimulated by the CTBT has focused attention on small seismic events that may be clandestine nuclear explosions. Small events are recorded primarily at regional distances, perhaps with a few reported teleseismic phases. The on-site inspection provisions of the CTBT also require the locations of these small events to be of high quality. The focus of research efforts motivated by the technical requirements of the CTBT, therefore, is on regional locations with a sparse network of recording stations.

[5] Our concentration will be on travel time models derived from a "global 3D seismic model," in contrast with travel time models that derive from local models or directly from observations of regionally propagating seismic phases such as $P_{n}$. Although high-quality regional travel time observations from well-located events are available in some regions of the world (e.g., China, parts of Europe, Japan, the western U.S., parts of Russia, and the former Soviet republics, etc.), this information is sparse within a worldwide context and may exist only for certain phases, most commonly $P_{n}$. The advantage of using a global $3 \mathrm{D}$ seismic model to predict regional travel times is that the model exists everywhere and can be used to predict the travel times of all seismic phases, although probably not with equal accuracy. If they are sufficiently accurate, the travel times computed using a global 3D model would provide the foundation on which to build future improvements such as assimilating observations of regional phases and regional travel time models where they exist. The assimilation of regional empirical information, however, requires international cooperation as well as a strong will to achieve. In lieu of this effort, travel times from a global 3D model across much of the Earth's surface may be the best feasible alternative, now and in the near future. They also provide a benchmark to improve upon in developing future capabilities, a role similar to that played by $1 \mathrm{D}$ travel time models now.

[6] To date, most published attempts to improve body wave travel time models have been devoted to improving teleseismic location capabilities by concentrating on the application of current generation 1D and 3D mantle models. For example, Engdahl et al. [1998] showed that global improvements in teleseismic locations are possible by applying new methods using the 1D model AK135 [Kennett et al., 1995]. Several researchers have investigated how the use of 3D tomographic models of the whole mantle affect hypocenter determinations based on teleseismic travel time data [e.g., Smith and Ekström, 1996; Antolik et al., 2001; Chen and Willemann, 2001]. These studies established that teleseismic mislocations are reduced relative to $1 \mathrm{D}$ model locations (e.g., Jeffreys-Bullen travel-time tables, preliminary reference Earth model (PREM) [Dziewonski and Anderson, 1981], IASP91 [Kennett and Engdahl, 1991]) when recent generation 3D mantle models based on either global [e.g., Su et al., 1994; Su and Dziewonski, 1997] or local basis functions [e.g., van der Hilst et al., 1997; Bijwaard et al., 1998; Boschi and Dziewonski, 1999] are applied. Efforts to predict teleseismic travel times with empirical teleseismic heterogeneity corrections have been more rare but show promise [e.g., Piromallo and Morelli, 2001].

[7] At regional distances, travel time predictions depend on the ability to model the crust and upper mantle. Regional travel time predictions are less accurate than teleseismic predictions because heterogeneity is much stronger and because data that constrain the crust and upper mantle are more limited in distribution and somewhat more difficult to interpret unambiguously. For example, regional triplication crossover distances are highly variable, which makes it difficult to identify phases correctly. This is true both for $P_{n}$ triplications as well as for distinguishing $P_{n}$ from $P$ arrivals. For these reasons, model-based approaches to predicting regional travel times [e.g., Firbas, 2000] have played a subordinate role to the development of purely empirical corrections [e.g., Myers and Schultz, 2000] that may be combined with spatial interpolation schemes [e.g., Schultz et al., 1998].

[8] The result is that the ability of 3D models, particularly global models, to predict regional travel times remains largely uninvestigated, and consequently, the applicability of $3 \mathrm{D}$ models to the problem of regional location is poorly understood. The purpose of this paper is to help fill in this gap in knowledge. Although our concentration is on Eurasia, the general features of the results should also hold for shallow events on other continents.

[9] We are able to perform the study of the utility of a global 3D model to improve regional locations because of two recent advances. First, we have developed a global 3D model of the crust and uppermost mantle that is designed specifically to be used for predicting regional travel times. To predict reliable regional travel times, it is first desirable that the model exists throughout the region of study. It is also necessary for attention to be paid to the crustal part of the model and, because regional travel times are controlled largely by the turning point of the ray, to the vertical gradient of the model. For regional travel times the vertical resolution is probably more important than the lateral resolution of the model. To satisfy these criteria, we use a $3 \mathrm{D} v_{s}$ model derived from surface wave dispersion which we convert to $v_{p}$ by applying information about the thermoelastic properties of an assumed mantle composition. The use of a $v_{s}$ model to predict regional $v_{p}$ travel times is not ideal but is the consequence of the existence of much better information about upper mantle $v_{s}$ than $v_{p}$ structure.

[10] The second advance is the development of a unique database of nearly 1000 "ground truth" (GT) locations in 23 event clusters across much of Eurasia. These locations, together with the groomed arrival time data set and the empirical phase path anomalies that emerge for each cluster, provide information needed to determine the capability of any travel time model or set of empirical travel time correction surfaces to predict regional travel times and locate seismic events using regional travel time data alone.

[11] We restrict the study to the use of $P$ and $P_{n}$ travel times for stations within $20^{\circ}$ of the source locations. While optimal regional locations would include crustal phases as well as later $P$ phases and $S$ phases, the consideration of these phases is not necessary to test the performance of the 3D model and, in fact, unnecessarily complicates the interpretation of the location exercise. 


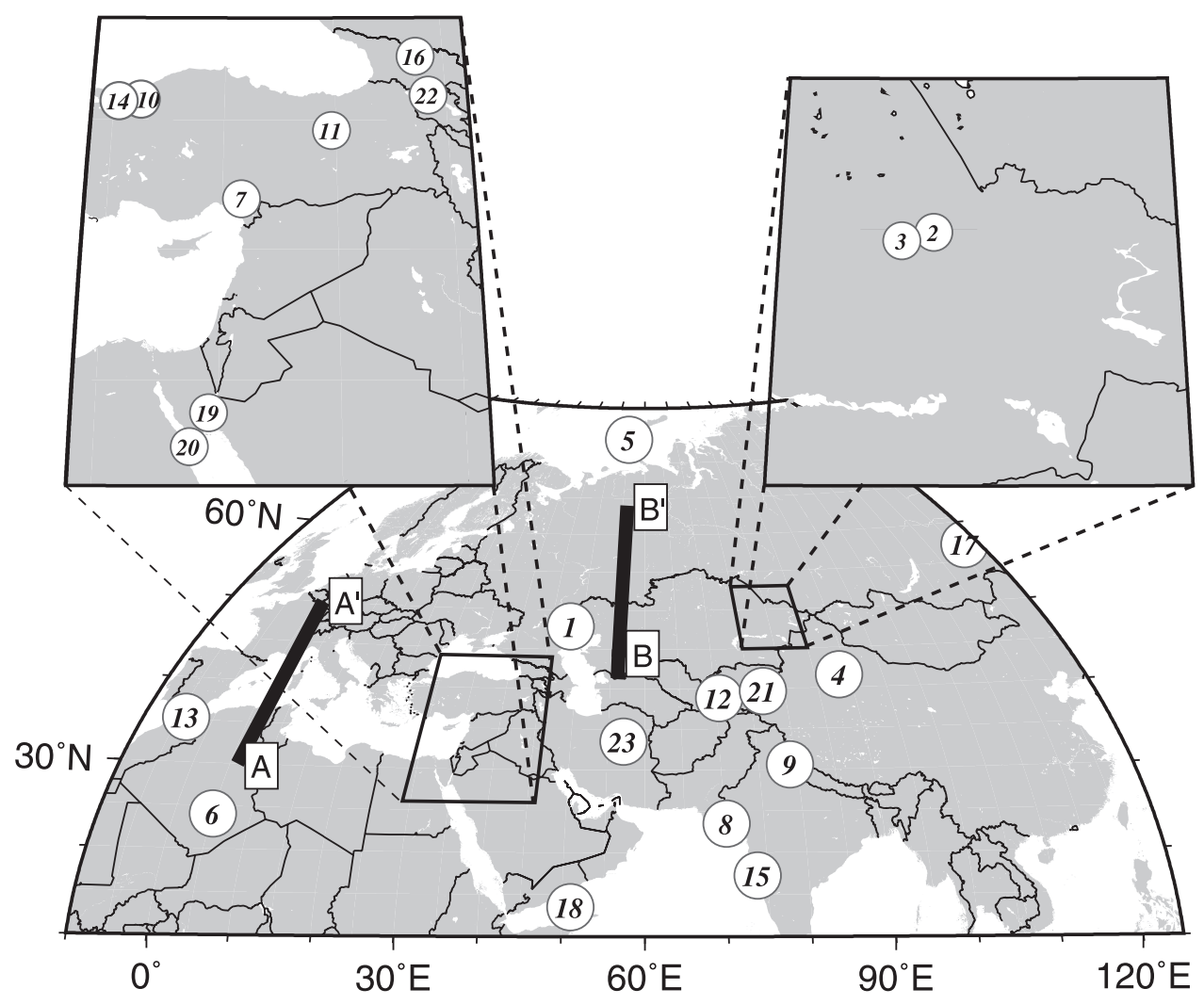

Figure 1. Locations of the explosion and earthquake clusters. Numbers refer to the clusters identified in Table 1. Lines $A-A^{\prime}$ and $B-B^{\prime}$ refer to the vertical model profiles shown in Figure 8.

[12] In section 2 we discuss the procedure used to construct the database of GT locations, the groomed arrival time data set, and the empirical phase path anomalies for each event cluster. In section 3 we discuss the means used to assess the 3D model. The 3D model construction and the ray-tracing procedure are discussed in section 4 . The first test of the $3 \mathrm{D}$ model is its ability to predict regional travel times. We discuss the fit to the empirical phase path anomalies in section 5. The second test of the 3D model is the ability to locate the GT events using regional data alone. The grid search location procedure is described in section 6 , and the location tests are presented in section 7 .

\section{Validating Data Set}

\subsection{Motivation}

[13] The assessment of a seismic velocity model requires a validating data set that is independent of the data used to derive the model. For this study we have assembled a data set of seismic events whose locations and origin times are known with greater than usual accuracy, either because they have been located with a local seismic network or because they were anthropogenic explosions. These so-called "ground truth" events are used to obtain reliable empirical estimates of source-station path anomalies (relative to a 1D reference model) that can be compared with predictions from seismic models. The known locations of the GT events can also be compared to locations obtained from seismic models.

[14] In this section we discuss the development of the validating data set by multiple event relocation of clustered earthquake and explosion sequences in Eurasia and northern Africa. Primarily, we use phase arrival time data reported to the ISC and to the NEIS, but for some clusters we have obtained additional data (usually at regional distances) from other sources. The arrival time data are first "groomed" on an event by event basis, using a procedure described by Engdahl et al. [1998] in the development of a catalog of events referred to as the EHB catalog. A multiple event location method is then used to refine the locations and identify outliers in the arrival time data. The resulting catalog of GT events, the groomed travel time database, and the empirical phase path anomalies create a database that can be used in experiments to assess 3D models and to address systematic errors in event location.

[15] The ground truth events occur in the clusters shown in Figure 1 and are listed in Table 1.

\subsection{GT Location Database}

[16] We seek clusters of earthquakes where at least one of the events has been very well located by a local seismic network or by a temporary deployment of instruments, commonly in aftershock studies. We have used events from 1964 to 2001 in this study. The clusters typically are 50$100 \mathrm{~km}$ across and comprise up to $\sim 100$ events of magnitude 3.5 or greater that are well recorded at regional and teleseismic distances.

[17] The multiple event location method used in this study is based on the Hypocentroidal Decomposition (HDC) method [Jordan and Sverdrup, 1981], which is schematically illustrated in Figure 2. The EHB single-event locations are used as the starting locations for the HDC 
Table 1. Cluster Parameters for Explosions, GT5 Earthquakes, and GT10 Earthquakes

\begin{tabular}{|c|c|c|c|c|c|c|c|c|}
\hline & Latitude, ${ }^{a}$ deg & Longitude, ${ }^{\mathrm{a}} \mathrm{deg}$ & Depth, ${ }^{\mathrm{a}} \mathrm{km}$ & $\Delta t_{0},{ }^{\mathrm{b}} \mathrm{s}$ & $\mathrm{n}_{\text {evt }}^{\mathrm{c}}$ & $\mathrm{n}_{\mathrm{ref}}^{\mathrm{d}}$ & $\mathrm{GT}_{x}^{\mathrm{e}}$ & Name \\
\hline \multicolumn{9}{|l|}{ Cluster number } \\
\hline 1 & 47.875 & 48.139 & 0.1 & 0.53 & 7 & 7 & GT1 & Azgir \\
\hline 2 & 49.954 & 78.871 & 0.0 & 0.81 & 100 & 100 & GT1-2 & Balapan \\
\hline 3 & 49.784 & 78.072 & 0.0 & 0.66 & 151 & 146 & GT1-2 & Degelen \\
\hline 4 & 41.580 & 88.605 & 0.0 & 0.43 & 20 & 13 & GT1-2 & Lop Nor \\
\hline 5 & 73.350 & 54.820 & 0.0 & -1.65 & 29 & 28 & GT1-2 & Novaya \\
\hline 6 & 24.049 & 5.040 & 0.0 & -0.08 & 5 & 5 & GT0 & Sahara \\
\hline 7 & 36.938 & 35.825 & 33.6 & -2.89 & 24 & 4 & GT5 & Adana \\
\hline 8 & 23.486 & 70.265 & 19.6 & 0.36 & 107 & 6 & GT5 & Bhuj \\
\hline 9 & 30.590 & 79.124 & 12.1 & -0.18 & 86 & 8 & GT5 & Chamoli \\
\hline 10 & 40.798 & 31.219 & 9.1 & -0.64 & 41 & 2 & GT5 & Duzce \\
\hline 11 & 39.588 & 39.805 & 6.4 & -1.73 & 9 & 3 & GT5 & Erzin \\
\hline 12 & 38.822 & 70.560 & 7.5 & -1.55 & 28 & 4 & GT5 & Garm \\
\hline 13 & 35.235 & -3.930 & 6.2 & -0.91 & 38 & 3 & GT5 & Hoceima \\
\hline 14 & 40.740 & 30.223 & 10.4 & -0.51 & 34 & 5 & GT5 & Izmit \\
\hline 15 & 17.236 & 73.748 & 8.2 & -0.29 & 31 & 10 & GT5 & Koyna \\
\hline 16 & 42.475 & 43.737 & 7.0 & -1.28 & 35 & 5 & GT5 & Racha \\
\hline 17 & 57.092 & 122.276 & 31.5 & -1.53 & 8 & 3 & GT5 & Siberia \\
\hline 18 & 13.513 & 51.069 & 10.0 & -0.45 & 55 & 5 & GT10 & Aden \\
\hline 19 & 28.754 & 34.608 & 14.0 & -1.94 & 36 & 1 & GT10 & Aqaba \\
\hline 20 & 27.482 & 33.864 & 12.8 & -1.49 & 27 & 1 & GT10 & Gubal \\
\hline 21 & 39.660 & 76.988 & 19.6 & -2.75 & 72 & 1 & GT10 & Jiashi \\
\hline 22 & 40.957 & 44.215 & 5.6 & -1.60 & 11 & 2 & GT10 & Spitak \\
\hline 23 & 33.479 & 57.111 & 14.6 & -1.95 & 35 & 2 & GT10 & Tabas \\
\hline Explosions & & & & & 312 & 299 & & \\
\hline GT5 earthquakes & & & & & 441 & 53 & & \\
\hline GT10 earthquakes & & & & & 236 & 12 & & \\
\hline Total & & & & & 989 & 314 & & \\
\hline
\end{tabular}

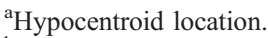

${ }^{\mathrm{b}}$ Cluster time baseline shift applied to teleseismic andregional data.

${ }^{\mathrm{c}}$ Number of GT events in the cluster.

${ }^{\mathrm{d}}$ Number of reference events in the cluster.

${ }^{\mathrm{e}} 95 \%$ confidence in location accuracy better than $x \mathrm{~km}$.

analysis, which converges in several iterations. We perform HDC analysis many times on each cluster, however, in the process of identifying outliers and estimating empirical reading errors.

[18] The depths for all events were fixed in the HDC analysis. We fixed depths at the local network determination of focal depth for those events for which we have that information and at an optimum depth (usually an average of the local network depths) for all remaining events in the cluster. To ensure that no gross errors in the assumed focal depths were made, we also examined reported depth phases at teleseismic distances [Engdahl et al., 1998].

[19] We refer to the resulting set of 989 locations listed in Table 1 as the GT locations. The accuracy of the GT locations and the shift in the origin time ("cluster time baseline shift") are discussed further in the following paragraphs.

[20] The reference event source parameters, which form the heart of the GT database, were compiled from many sources but were based exclusively on work done by the original investigators in each source region. We attempt to validate the claimed accuracy and assign a GT level of accuracy by analyzing the local network data and by performing tests of consistency with the HDC results. We discovered that many proposed reference events are, in fact, seriously mislocated. The consistency between the relative locations as determined by HDC analysis of global arrival time data and the relative locations derived from the reference event data is one of the criteria we use to validate candidate reference events. Shifts in epicenter and origin time to match the reference event locations are typically in the range of $5-15 \mathrm{~km}$ and $\pm 2 \mathrm{~s}$, respectively.

[21] We follow I. Bondar et al. (Epicenter accuracy based on seismic network criteria, submitted to Geophysical Journal International, 2003) and represent location confidence bounds using the ground truth GTXC\% classification, where the " $X$ " suffix designates location accuracy in $\mathrm{km}$ and $\mathrm{C} \%$ is the percent confidence. For simplicity here we report only $95 \%$ confidence bounds so that, for example, a GT5 classification represents 95\% confidence in location accuracy of $5 \mathrm{~km}$ or better.

[22] We use the "GT level" classifications in two senses. First, we use them in the sense of the accuracy level of individual reference events, as discussed in the following paragraphs. Second, we use the same concept to describe the level of accuracy of entire clusters after shifting to best match the reference locations. The GT level assigned to a cluster is more subjective, related to the GT level of individual reference events, the number of reference events, the degree of consistency between the relative locations as expressed by the HDC analysis and reference data, and other factors. For example, the Aqaba cluster is calibrated by a single reference event which qualifies as GT5, but we assign the cluster a GT10 level of accuracy because there is only a single reference event and because the event occurred in a region of very strong lateral heterogeneity, the transition from continental to oceanic lithosphere.

[23] We shift the hypocentroid in space and time to achieve the best fit for absolute locations and origin times between the HDC-derived locations and the reference event 


\section{Cluster Vectors, Relative Location}

\section{Hypocentroid, Absolute Location}
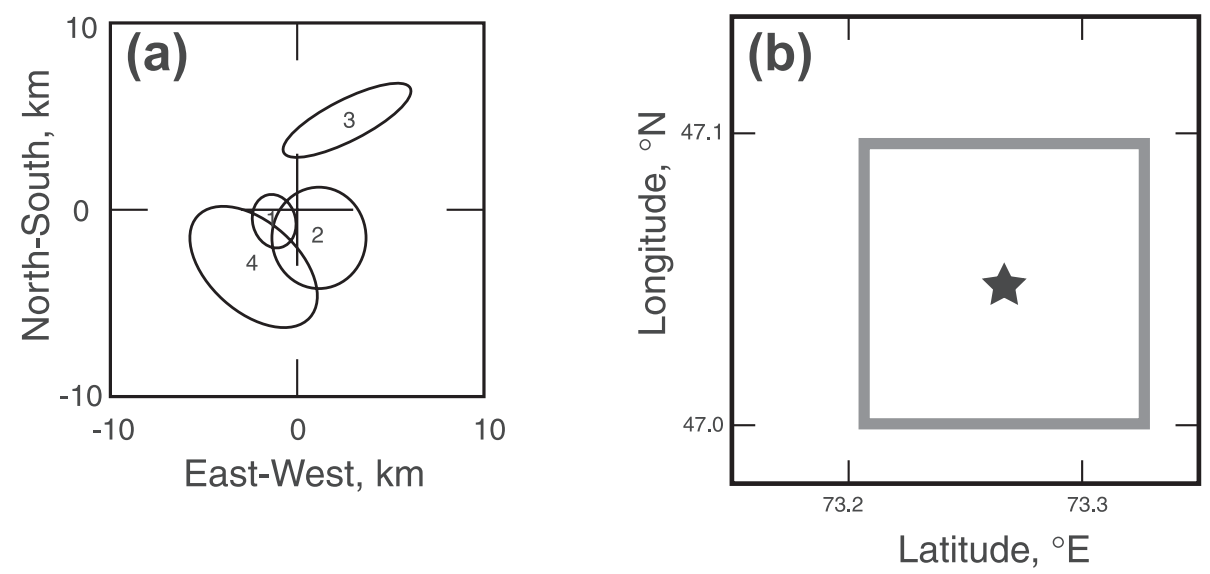

Cluster Vectors, Absolute Location

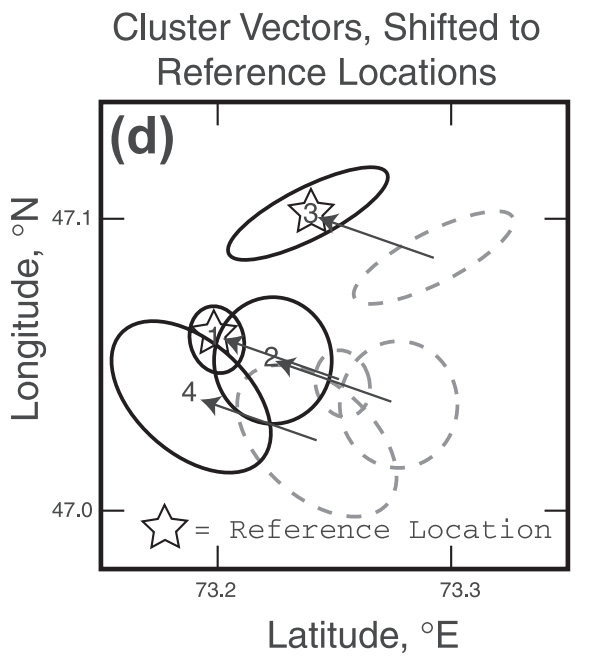

Figure 2. Schematic of the HDC analysis used to generate the GT database in this study. (a) Relative locations of cluster event epicenters ("cluster vectors") shown with $90 \%$ confidence ellipses. Locations are relative to the hypocentroid, the geometric mean of current absolute locations of all events. (b) The hypocentroid (star) located using all cluster event arrival time data (appropriately shifted) as if it were an earthquake, using the 1D model AK135. The box corresponds to Figure 2a. (c) Relative locations from Figure $2 \mathrm{a}$ added to the absolute location of the hypocentroid in Figure $2 \mathrm{~b}$ to give absolute locations for all events in the cluster, with confidence ellipses scaled from Figure 2a. (d) The location bias, removed by shifting the cluster to match the reference event locations (from independent local seismic data) that have been obtained for this cluster. Reference locations for events 1 and 3 are shown by open stars. All cluster events are shifted by the same vector, the average of the shifts being calculated from the reference locations and the corresponding HDC locations in Figure 2c. The shifted locations for all cluster events in Figure 2d compose the GT location database.

locations, as illustrated in Figure 2d. The "cluster time baseline shift" is the average difference between the reference event origin times and the origin times obtained by HDC analysis for those same events (Table 1). This correction is added to the HDC-derived origin times to produce a best estimate of absolute origin times. Positive corrections (i.e., shorter travel times) indicate faster velocities relative to AK135. The cluster time baseline shift arises, in part, from differences between the 1D model travel times used in the HDC analysis and the true travel times but may also reflect bias in the reference event origin times. Myers and Schultz [2001] have shown that origin times estimated from local network data can be biased by several seconds if the local velocity model is not well calibrated, even though the hypocenters may be estimated with high accuracy. The cluster time baseline shifts assist in phase identification and are also used to compare results between clusters; they are included in estimates of empirical phase path anomalies relative to AK135, as discussed in section 2.4.

[24] This method has resulted in a database of 23 event clusters, including 6 explosion clusters with source locations generally known to be better than $2 \mathrm{~km}$ and 17 earthquake clusters, 11 of whose locations are believed to be accurate to within $5 \mathrm{~km}$ and the remainder to within $10 \mathrm{~km}$. There are 989 events that compose these 23 clusters, of which 753 are GT5 or better. The locations of the clusters studied are plotted in Figure 1. Relevant parameters for all clusters are listed in Table 1. The location and depth given 
Table 2. Number of Travel Times in the Groomed Arrival Time and the Empirical Phase Path Anomaly Data Sets

\begin{tabular}{lccccc}
\hline & \multicolumn{2}{c}{$\begin{array}{c}\text { Groomed Arrival } \\
\text { Times }\end{array}$} & & \multicolumn{2}{c}{$\begin{array}{c}\text { Empirical Path } \\
\text { Anomalies }\end{array}$} \\
\cline { 2 - 3 } \cline { 6 - 6 } & $P_{n}$ & $P$ & & $P_{n}$ & $P$ \\
\hline Explosions & 1521 & 477 & & 121 & 35 \\
GT5 & 8974 & 1380 & & 558 & 108 \\
GT10 & 3106 & 539 & & 157 & 35 \\
Total & 13,601 & 2396 & 836 & 178 \\
\hline
\end{tabular}

are for the shifted hypocentroid, representing the best fit to reference event locations.

\subsection{Groomed Arrival Time Data Set}

[25] The method of multiple event location efficiently rejects outliers, which results in a data set of "groomed" arrival times for each of the events in the GT database. The number of these data is listed in Table 2, and Figure 3 shows a plot of the $P_{n}$ and $P$ residuals for all groomed arrival times included in this database, adjusted by the cluster time baseline shift. Estimates of the residual median and spread show considerable variation over the regional distance range. In particular, residuals for $P_{n}$ arrivals between $\sim 9^{\circ}$ and $17^{\circ}$, corresponding to ray paths bottoming in the lithosphere well below the crust and perhaps encountering low-velocity zones, are more spread, with a maximum spread at distances of $12^{\circ}-13^{\circ}$. A contributing factor to this spread at larger regional distances is the difficulty of phase identification, for example, distinguishing between various $P_{n}$ branches or between $P_{n}$ and $P$ in regions where the crossover distance between the first-arriving branches of these phases is poorly known.

\subsection{Empirical Phase Path Anomalies}

[26] The basic premise of all multiple event location methods is that path anomalies from each station to all observed events in a given cluster are correlated. Thus multiple event location analysis produces robust estimates of source-station path anomalies that are far more difficult to extract from single event location catalogs. The set of groomed residuals for regional $P$ and $P_{n}$, relative to shifted hypocenters derived by HDC analysis and adjusted for cluster time baseline shifts, are used to calculate sourcestation phase path anomalies. These anomalies are estimated relative to the 1D reference model AK135. Medians and spreads for all groomed residuals for each cluster are calculated for the phases of interest (here primarily $P$ and $P_{n}$ ) at each of the reporting stations for that cluster. The resulting source-station "empirical phase path anomalies" (the median) are accepted with a minimum requirement of five observations and a spread of $<1.40 \mathrm{~s}$ for $P$-type phases. ("Spread" is a robust analog to the standard deviation.)

[27] At regional distances, there are $836 P_{n}$ and $178 P$ path anomalies. Results are plotted in Figure 4. These empirical estimates range from about -7.5 to $+5.0 \mathrm{~s}$, with the largest anomalies occurring at distances from $11^{\circ}$ to $18^{\circ}$ (similar to Figure 3). In this distance range, $P_{n}$ typically has a triplication and $P$ has a back branch (Figure $4 \mathrm{~b}$ ), making phase identification difficult.

\section{Evaluation Metric}

[28] In section 2 we described three data sets that are useful for assessing 3D seismic models. First, there is the set of 989 GT locations that are available to test location capabilities. In fact, only 753 of these events are identified

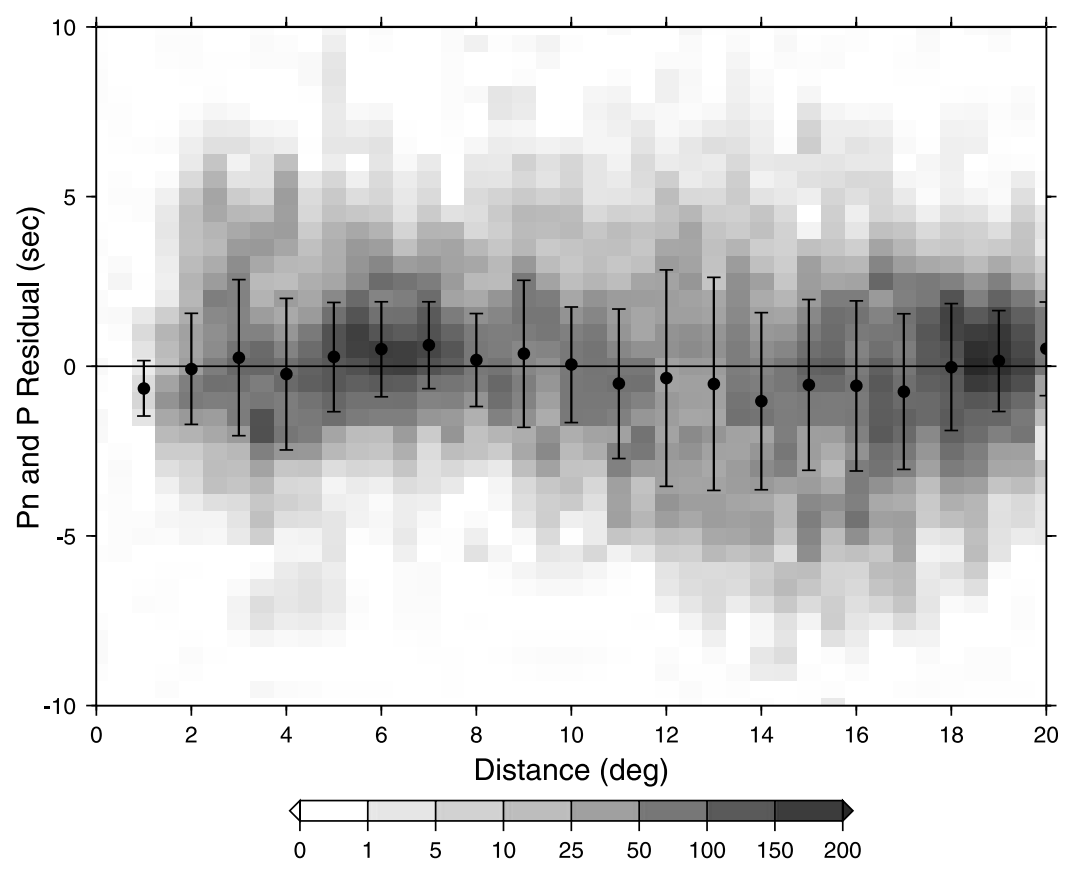

Figure 3. Residual density plot for $P_{n}$ and $P$ phases in the groomed arrival time data set. Residuals are taken with respect to AK135 travel times. Station cluster residuals corrected for the cluster event static are binned at $0.5^{\circ}$ in distance and $0.5 \mathrm{~s}$ in time. Bin hit counts are plotted according to the scale. Estimates of the residual median and spread at $1^{\circ}$ intervals are also plotted as circles and vertical lines, respectively. 
(a)

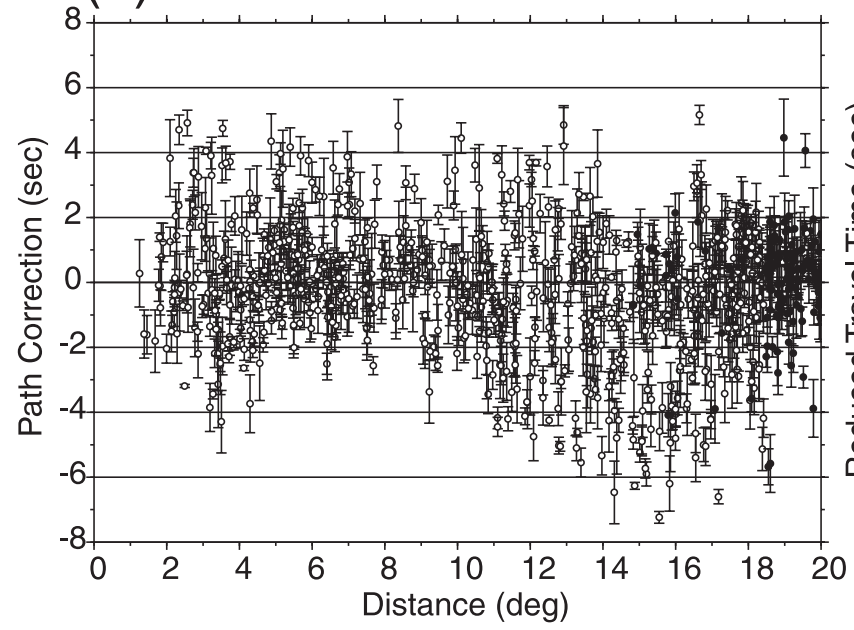

(b)

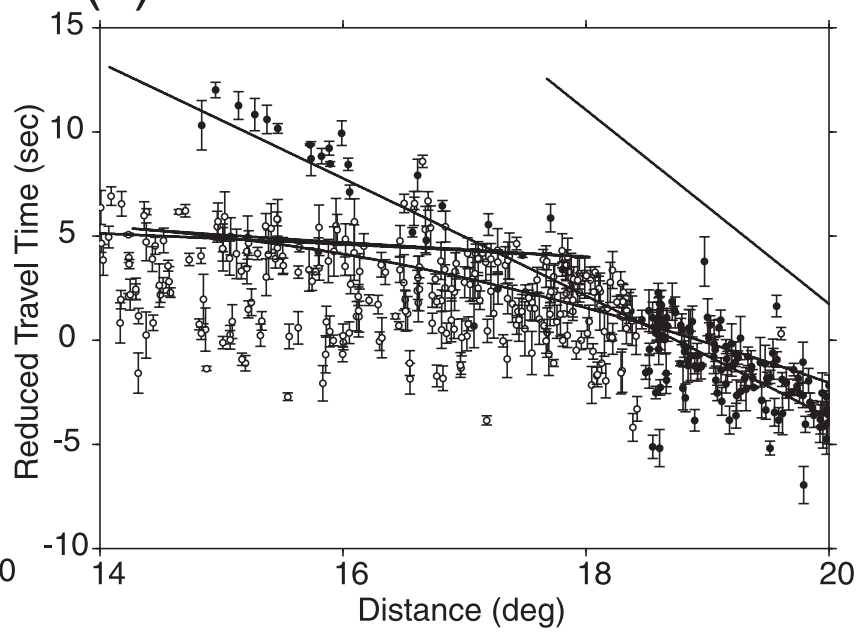

Figure 4. Reduced $P_{n}$ (white) and $P$ (black) empirical phase path anomalies plotted as the median and spread estimates with respect to distance. Travel times are corrected for cluster time baseline shifts. (a) Results presented as residuals with respect to the AK135 travel times. (b) Results presented near the $P_{n} / P$ crossover as reduced travel times (relative to $8.0 \mathrm{~km} \mathrm{~s}^{-1}$ ). AK135-predicted $P_{n}$ and $P$ travel time branches are also shown.

as GT5 or better, and it is these events that will be most useful in this study. Second, there are the groomed travel time data, particularly regional $P$ and $P_{n}$, from the ISC and NEIS bulletins as well as some data from regional networks that formed the basis for the HDC analyses. These data are used to relocate the GT events in section 7. Finally, there are the empirical phase path anomalies that, in section 5, are compared with the travel times predicted from several models (both 1D and 3D).

[29] Studies aimed at evaluating the location capabilities of certain models or location techniques commonly concentrate exclusively on the accuracy of the locations relative to some benchmark. Although this is also an important part of the present study, we argue that the ability to model regional travel time data is a better measure of the quality of 3D models and is, in fact, a more robust predictor of regional location capabilities. This is because evaluations based on location alone are complicated by a variety of factors that inhibit clear assessment, for example, variations in network geometry from one region to another, different mixes of regional phases, differential quality of reported travel times, and so forth. The carefully constructed empirical phase path anomaly data set gives us confidence that assessments of the fit to regional travel time data provide meaningful, relatively unambiguous information about the quality of the models. The groomed travel time data set alone is probably too noisy to be used for this purpose.

\section{3D Model and Travel Time Computation}

\subsection{Model Construction}

[30] The 3D model is based on broadband surface wave group and phase speed measurements. The group velocities were measured using the frequency-time method described by Ritzwoller and Levshin [1998], which involves analyst interaction to choose the frequency band of measurement and to guide the extraction of the fundamental mode from noise, scattered and multipathed signals, overtones, and fundamental modes of different wave types. We use group speed measurements from a 16 to $200 \mathrm{~s}$ period for Rayleigh waves and from a 16 to $150 \mathrm{~s}$ period for Love waves. The phase speed measurements were performed at Harvard University [Ekström et al., 1997] and Utrecht University [Trampert and Woodhouse, 1995] separately, and we merged these data sets. The phase speed measurements extend from 40 to $150 \mathrm{~s}$ for both Rayleigh and Love waves. We use measurements only from earthquakes shallower than $50 \mathrm{~km}$ to reduce the size of the source group time shifts, which we do not attempt to correct [Levshin et al., 1999]. All measurements are subjected to the quality control procedures described by Ritzwoller and Levshin [1998], but the number of group speed measurements has multiplied several times since that study.

[31] The construction of the group and phase speed maps uses the tomographic method described by Barmin et al. [2001], which is based on geometrical ray theory with intuitive Gaussian smoothing constraints to simulate surface wave sensitivities. We refer to this method as Gaussian tomography. In fact, we apply an update of this method [Ritzwoller et al., 2002a], referred to as diffraction tomography, which uses a simplified version of the scattering sensitivity kernels that emerge from the Born or Rytov approximations. Diffraction tomography accounts for path length-dependent sensitivity, wave front healing, and associated diffraction effects and provides a more accurate assessment of spatially variable resolution than do traditional tomographic methods. The resolution procedure is described by Barmin et al. [2001]. We produce a resolution surface at every nodal point on the globe, fit a cone to the surface in the neighborhood of each node, and define resolution as the half width of the base of the cone (or identically, the full width at half max). Surface wave resolution estimates averaged over the region of study are presented in Figure 5. Surface wave Fresnel zones widen 


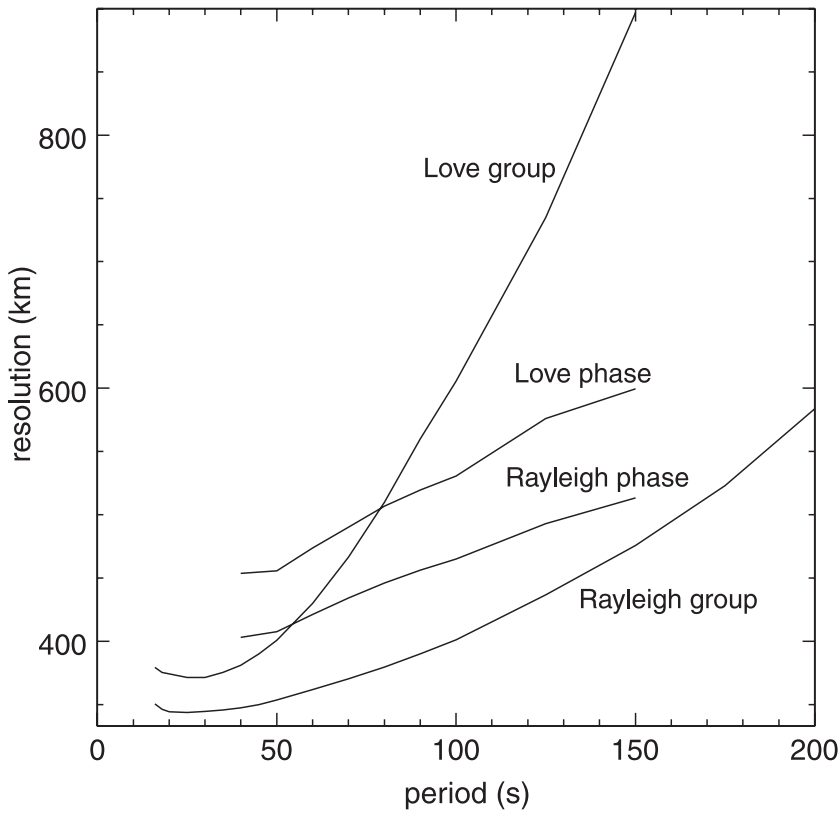

Figure 5. Resolution of the dispersion maps averaged across the region of study (Figure 1).

appreciably at long periods and narrow only near sources and receivers so resolution is best at short periods and in areas with sources or receivers. The dispersion maps are produced on a $2^{\circ} \times 2^{\circ}$ grid worldwide. Diffraction
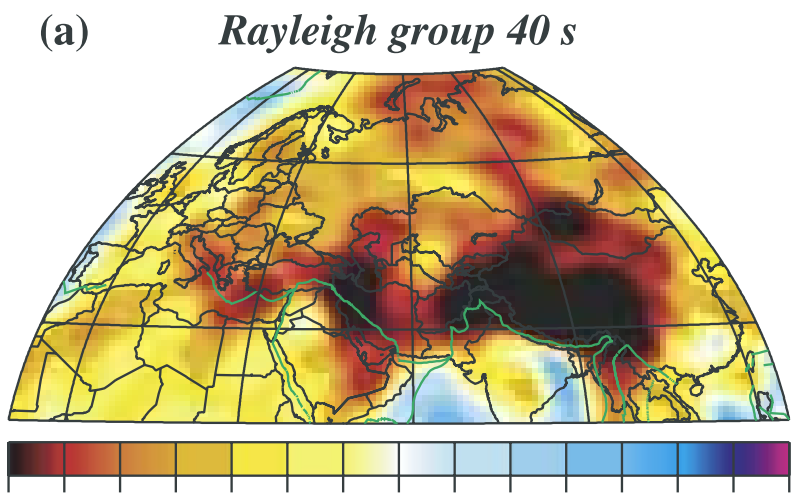

$-15.0-9.0-7.5-6.0-4.5-3.0-1.50 .01 .53 .04 .56 .07 .59 .015 .0-10$

(c)

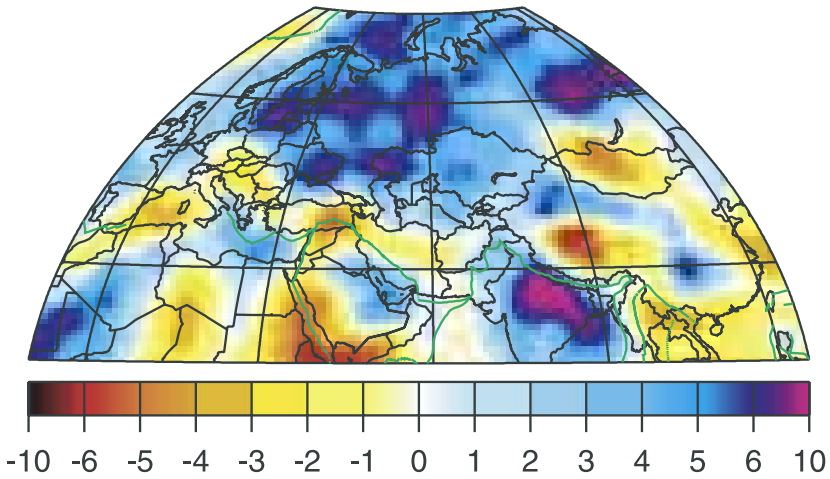

tomography affects the amplitude and geometry of the dispersion features, particularly at long period, as described by Ritzwoller et al. [2002a]. Figures 6a and 6b show two examples of surface wave dispersion maps across the region of study, constructed with diffraction tomography.

[32] The shear velocity model is constructed using a Monte Carlo method, which is described in detail by Shapiro and Ritzwoller [2002]. The shear velocity model of Shapiro and Ritzwoller [2002] was based on Gaussian tomography and is referred to here as CUB1.0. The 3D shear velocity model we use here is based on diffraction tomography, and we will refer to it as CUB2.0. These models only include $v_{p}$ in the crust. The $v_{p}$ part of CUB2.0 in the mantle is derived by converting from $v_{s}$ using two different methods. We will distinguish between these two $v_{p}$ models by introducing suffixes to the names (CUB2.0 TH, CUB2.0_EMP), as discussed in section 4.2.

[33] The inversion for a velocity profile is performed at each node on a $2^{\circ} \times 2^{\circ}$ grid worldwide, producing an ensemble of acceptable models down to a depth of $400 \mathrm{~km}$. The model is constrained by a variety of a priori information, including the initial crustal model CRUST2.0 (G. Laske, personal communication, 2002) and the initial mantle model S20A of Ekström and Dziewonski [1998]. Perturbations are allowed, within specified tolerances, to both $v_{s}$ and $v_{p}$ in the crust, to $v_{s}$ in the mantle, and to Moho depth. The model is radially anisotropic $\left(v_{s h} \neq v_{s v}\right)$ from the Moho to a variable depth that averages $\sim 200 \mathrm{~km}$. The strength of radial anisotropy is constrained to decrease monotonically with depth, and crustal speeds are constrained to increase monotonically

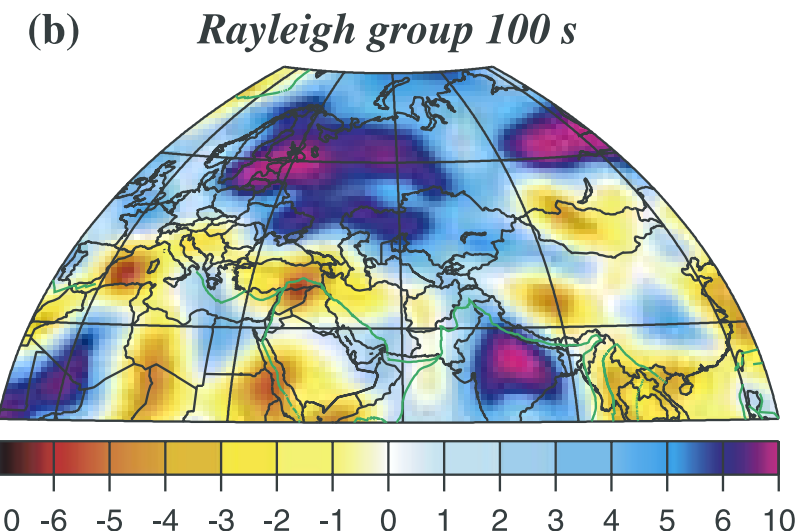

(d)

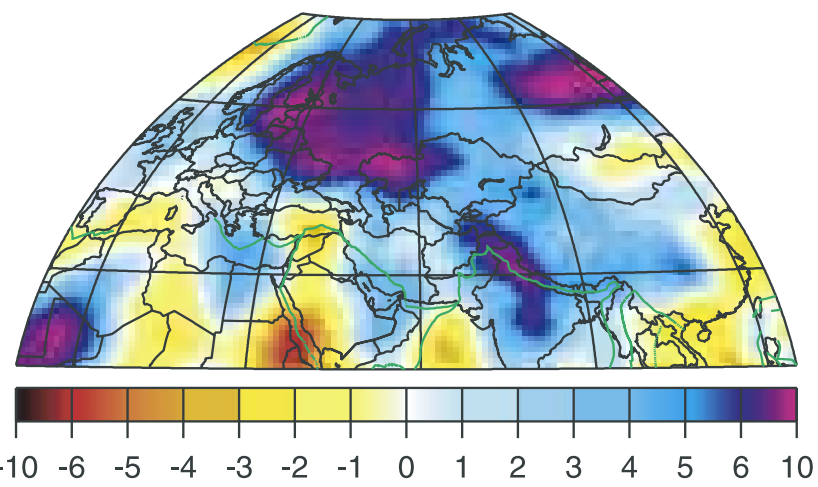

Figure 6. Dispersion maps and horizontal slices of the model: (a) Rayleigh group $40 \mathrm{~s}$; (b) Rayleigh group $100 \mathrm{~s}$; (c) $80 \mathrm{~km}$; and (d) $150 \mathrm{~km}$. 
a)
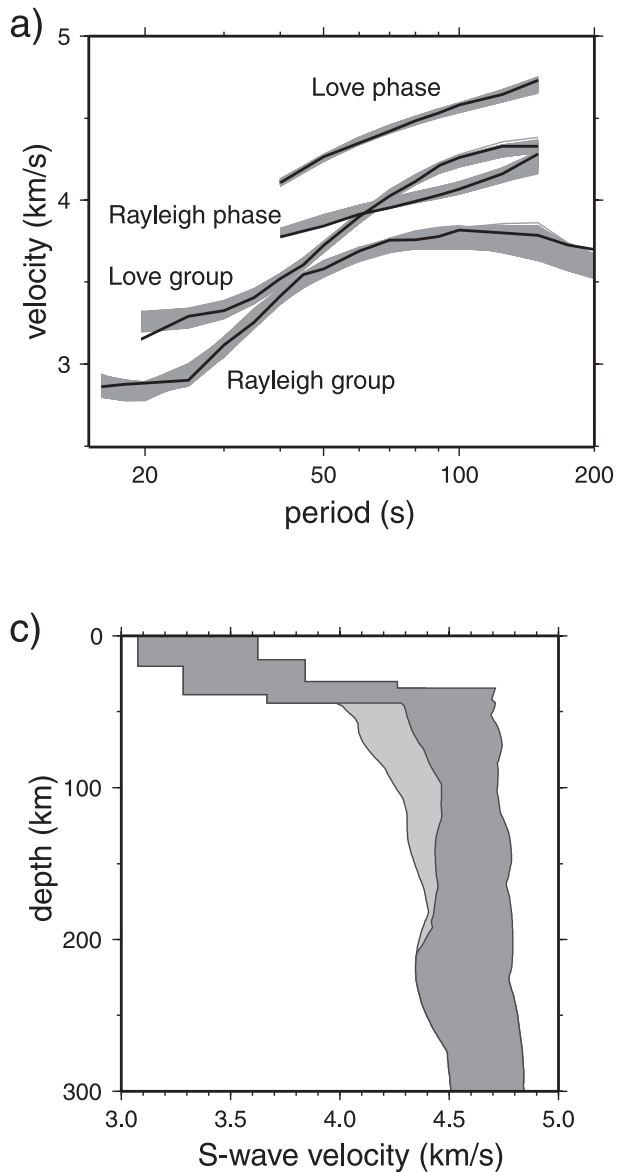
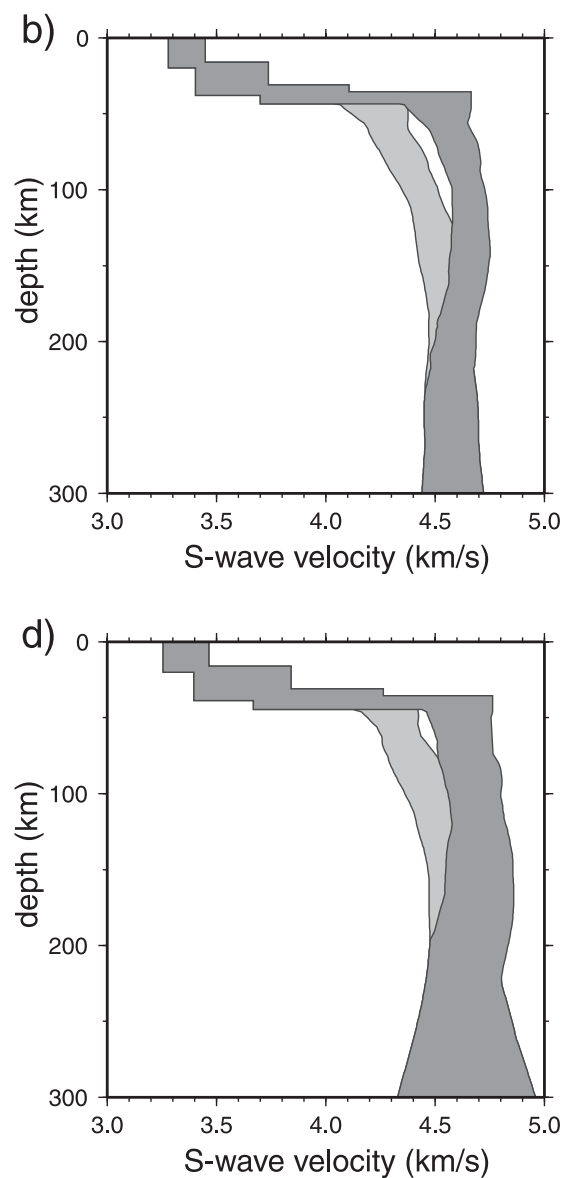

Figure 7. (a) Observed dispersion curves at a point in $\operatorname{Iran}\left(30^{\circ} \mathrm{N}, 60^{\circ} \mathrm{E}\right)$. The black lines are observations derived from the dispersion maps, and the shaded zones represent the range of dispersion curves from the ensemble of acceptable models shown in Figure 7b. Inversion results for three data sets: (b) simultaneous inversion of group and phase speeds (CUB2.0); (c) phase speed alone; and (d) group speed alone. The full width of the ensemble of acceptable models is indicated, where $v_{s h}$ is darkly shaded and $v_{s v}$ is lightly shaded.

with depth. Shapiro and Ritzwoller [2002] fully describe the set of constraints and a priori information.

[34] Figure 7 presents an example of the results of the Monte Carlo inversion at a single point. The center and half width of the ensemble of acceptable models summarize the model at each depth. The effective isotropic model, $v_{s}$, is defined as the average of $v_{s h}$ and $v_{s v}$ at each depth. Figures $7 \mathrm{~b}-7 \mathrm{~d}$ show that model uncertainties are reduced, and hence vertical resolution is improved appreciably by simultaneously inverting the group and phase speed curves. Using phase velocities alone produces large uncertainties in the crust and, consequently, also in the upper mantle. Inverting group velocities alone yields relatively small uncertainties in the crust and uppermost mantle due to measurements at periods shorter than $40 \mathrm{~s}$, but uncertainties deeper in the upper mantle are larger. When the phase and group velocities are inverted simultaneously, however, uncertainties are significantly reduced at all depths. In particular, the simultaneous inversion of broadband group and phase speed data in the presence of a priori constraints on allowable structures in the crust and upper mantle ameliorates the trade-off between crustal and upper mantle structures that plague inversions of surface waves in continental areas.
[35] Figures 6c-6d and Figure 8 present horizontal and vertical slices of the $v_{s}$ model to demonstrate the nature of the heterogeneities. It is noteworthy that the mantle features inferred from diffraction tomography tend to have larger amplitudes and extend deeper than those from Gaussian tomography. On the basis of the dispersion resolution information given in Figure 5, we infer that average lateral resolution is $\sim 500 \mathrm{~km}$ in the uppermost mantle but that it degrades with depth. As length scales in the model approach the estimated resolution, however, the amplitude of heterogeneity tends to be underestimated.

\subsection{Conversion of $v_{s}$ to $v_{p}$ in the Mantle}

[36] To be able to predict $P_{n}$ and $P$ travel times, the 3D $v_{s}$ model CUB2.0 must be converted to a $v_{p}$ model. There are two general approaches to doing this. The first is to use "empirical scaling relations" that convert $v_{s}$ anomalies into $v_{p}$ anomalies. The most successful of these map shear speed perturbations, $\delta v_{s}$, relative to a reference $S$ model, $v_{s_{0}}$, to compressional velocity perturbations, $\delta v_{p}$, relative to a reference $P$ model, $v_{p_{0}}$, where $d \ln v_{p} / d \ln v_{s}$ is then taken to be an empirically constrained constant that may be a function of depth but is usually depth invariant. The second approach is to use a "thermoelastic conversion" based on 


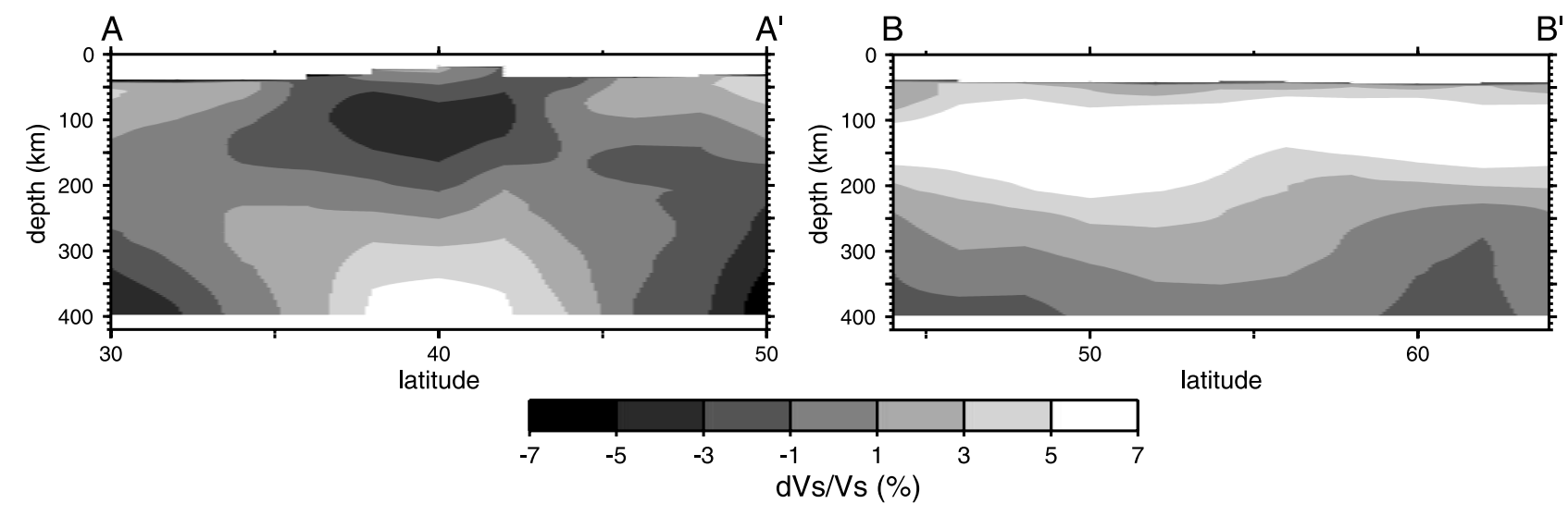

Figure 8. Vertical slices of the $v_{s}$ model from CUB2.0 plotted as percent deviation from AK135. Locations of the profiles are shown in Figure 1.

laboratory measurements of thermoelastic properties of mantle minerals and on models of the average mineralogical composition of the mantle. The $v_{p}$ model that results from CUB2.0 $v_{s}$ by the thermoelastic conversion will be referred to here as CUB2.0_TH, and the $v_{p}$ model derived from the empirical scaling relation $d \ln v_{s} / d \ln v_{p}=1.9$, in which the $1 \mathrm{D}$ reference model is AK135, will be called CUB2.0_EMP. We convert only isotropic $v_{s}$ to $v_{p}$. In the radially anisotropic part of CUB2.0 we therefore use $v_{s}=\left(v_{s v}+v_{s h}\right) / 2$.

[37] We prefer the thermoelastic conversion from $v_{s}$ to $v_{p}$ for two reasons. First, as we will show below, the thermoelastic conversion appears to work somewhat better in that the regional $P$ and $P_{n}$ empirical phase path anomalies are fit better by travel times predicted by CUB2.0_TH than by CUB2.0_EMP. Second, the thermoelastic conversion leads naturally to future improvement. It can be regionally tuned in a physically meaningful way by modifying the mineralogical composition and temperatures within the anelastic model, and it can be updated as better mineralogical data become available.

[38] The thermoelastic conversion between $v_{s}$ and $v_{p}$ in the mantle is mediated by a conversion to temperature. There have been numerous previous studies that have explored the relationship between the seismic velocities, temperature, and composition [e.g., Duffy and Anderson, 1989; Graham et al., 1989; Furlong et al., 1995; Sobolev et al., 1996; Goes et al., 2000; Röhm et al., 2000; Trampert et al., 2001; van Wijk et al., 2001]. The method we use here is based on that of Goes et al. [2000] and is described in detail by N. M. Shapiro and M. H. Ritzwoller (Thermodynamic constraints on seismic inversions, submitted to Geophysical Journal International, 2003, herinafter referred to as Shapiro and Ritzwoller, submitted manuscript, 2003). The mantle is considered to be composed of four principal minerals. The elastic moduli and density can be computed for each mineral independently as a function of temperature, pressure, and iron content, extrapolating values of each quantity at surface conditions to depth with zero iron content by using experimentally determined partial derivatives. For a specific mineralogical composition the elastic moduli and density, and hence the seismic velocities, are computed using the Voigt-Reuss-Hill mixing scheme. The result holds at high frequencies or very low temperatures, where anelasticity contributes minimally. At mantle temperatures and seismic frequencies, however, the temperature-velocity relation must include a correction for physical dispersion. Because uppermost mantle $Q$ is poorly known, we use the attenuation model of Minster and Anderson [1981] that relates $Q$ to temperature. We follow Sobolev et al. [1996] in specifying the parameters in this conversion (frequency exponent, activation energy, and volume), but we calibrate the amplitude of the correction based on the average shear velocity in the region of study and on an assumed average upper mantle temperature of $1400^{\circ} \mathrm{C}$ at $200 \mathrm{~km}$ depth. We use a single mineralogical composition here for the entire region of study, the average off-cratonic continental composition advocated by McDonough and Rudnick [1998]: 68\% olivine, 18\% orthopyroxene, $11 \%$ clinopyroxene, and $3 \%$ garnet, with an iron:magnesium ratio of $10 \%$.

[39] Figure 9a shows the resulting $v_{s}$ to $v_{p}$ thermoelastic conversion. Figure $9 \mathrm{~b}$ displays this conversion presented as the logarithmic scaling relation, $d \ln v_{s} / d \ln v_{p}$, which varies with both $v_{s}$ and depth. The $v_{s}$ profile from AK135 is overplotted, nearly paralleling the contours of the thermoelastic predictions. This illustrates why depth-independent values of the scaling relation tend to work fairly well in the upper mantle. For the values of $v_{s}$ in AK135 the thermoelastic prediction for the scaling relation is $d \ln v_{s} / d$ $\ln v_{p} \sim 1.6-1.8$. Figure $9 \mathrm{~b}$ also shows that the $v_{s}$ profile converted from the AK135 $v_{p}$ profile by the thermoelastic conversion agrees fairly well with the $v_{s}$ profile in AK135 at depths below $\sim 100 \mathrm{~km}$. The thermoelastic conversion between $v_{s}$ and $v_{p}$ differs appreciably from the $v_{s}$ and $v_{p}$ parts of AK135 only above $\sim 100 \mathrm{~km}$. Figure 10a exemplifies this by showing representative $v_{p}$ profiles from tectonic (e.g., A-A ${ }^{\prime}$ ) and platform (e.g., B-B') regions of CUB2.0_TH and CUB2.0_EMP. The empirical relation produces somewhat faster $v_{p}$ in the uppermost mantle than does the thermoelastic conversion.

\subsection{Travel Times and Correction Surfaces}

[40] To compute travel times for $P_{n}$ and $P$, we use a modified version of the 2D ray tracer developed by Cervený and Pšenčik [1984]. Villaseñor et al. [2003] shows that this code applied to the CUB 3D models agrees well with travel times from the finite difference code of Podvin and Lecompte [1991], modified to be applied on a spherical Earth. They also show that travel time variations from $3 \mathrm{D}$ 
a)

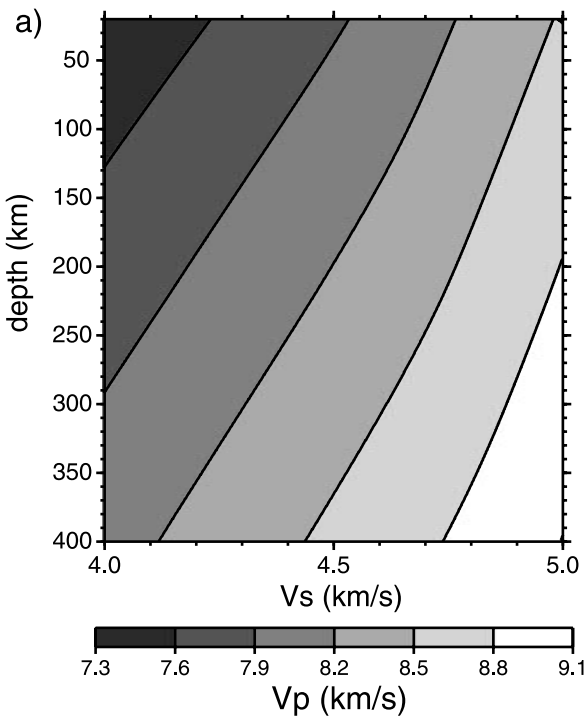

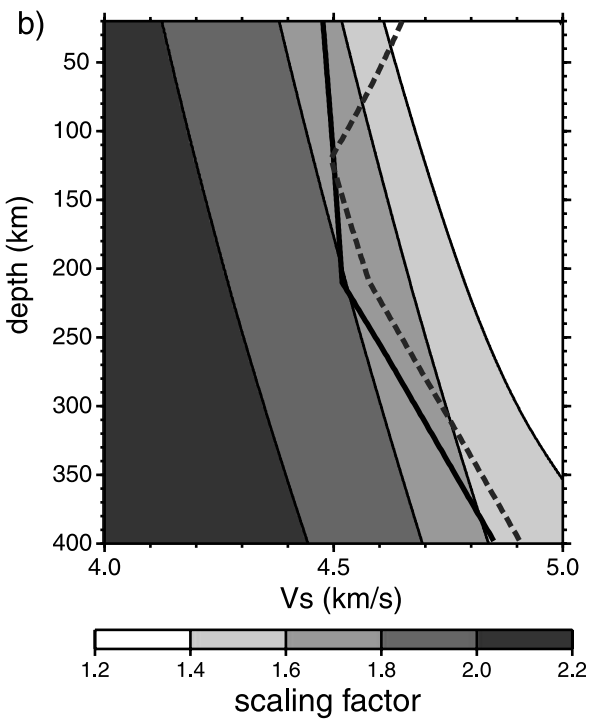

Figure 9. (a) Grid used for the thermoelastic $v_{s}$ to $v_{p}$ conversion. (b) The thermoelastic conversion presented as the logarithmic scaling factor $d \ln v_{s} / d \ln v_{p}$. The solid line is $v_{s}$ from the 1D model AK135, and the dashed line is $v_{s}$ converted from AK135 $v_{p}$ by the thermoelastic conversion.

excursions in regional rays through the CUB 3D models are small and do not substantiate the computational cost of computing $3 \mathrm{D}$ rays. Even in $2 \mathrm{D}$, however, $P_{n}$ is a very complex phase, as the rays and travel time curves shown in Figure 11 illustrate.

[41] The travel times of the $P_{n}$ phase from the 3D $P$ models derived with the two conversion schemes can differ appreciably, as Figure 12 shows. In a geographically averaged sense, CUB2.0 EMP produces $P_{n}$ travel times that are $\sim 1 \mathrm{~s}$ faster than $P_{n}$ times from CUB2.0 TH. This discrepancy is strongest in tectonic areas, but in shield areas the thermoelastic conversion actually tends to produce faster times at distances beyond $\sim 100 \mathrm{~km}$ because the deeper parts of the model beneath the shallow mantle lid are faster and rays tend to dive deeper. The difference between the empirical and thermoelastically

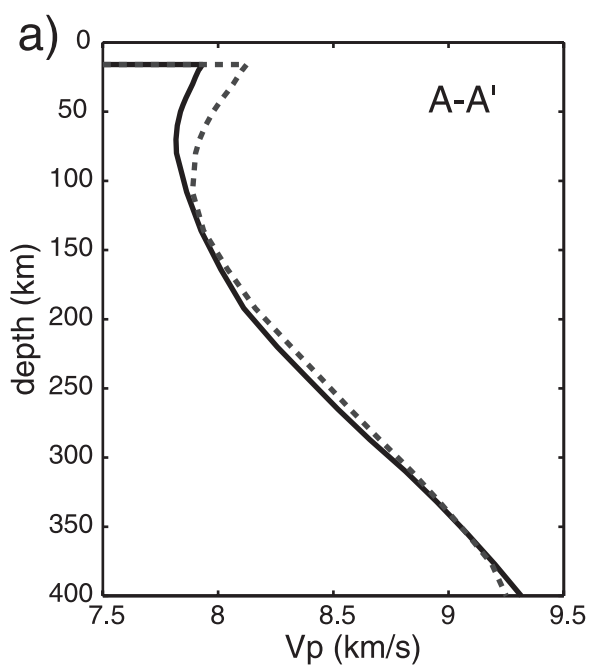

converted $P_{n}$ travel times is largest at distances beyond $\sim 2000 \mathrm{~km}$. This is probably because second-order pressure dependencies are needed in the thermoelastic conversion for rays turning deeper than $\sim 250 \mathrm{~km}$. Future advances in the thermoelastic conversion based on finite strain theory may correct this effect, but for the present study it is a moot point, at least for $P_{n}$, which is rarely observed beyond $2000 \mathrm{~km}$. The use of the thermoelastic conversion for longer baseline $P$ phases, however, will need to take this into consideration.

[42] For the validation exercises in sections 5 and 7 we compute "travel time correction surfaces" for $P_{n}$ and $P$ for all of the 854 stations in the groomed arrival time data set. Separate surfaces are computed for a discrete set of hypothesized event depths $(0,10,20,30$, and $40 \mathrm{~km})$ and are then interpolated to provide correction surfaces for events

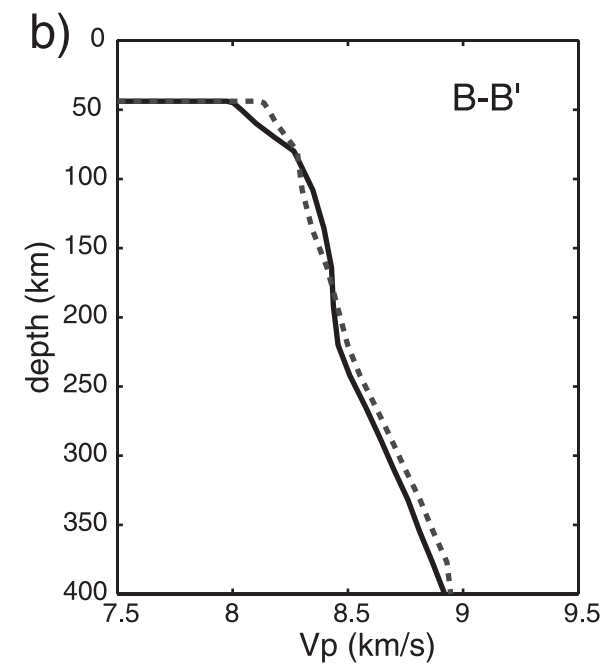

Figure 10. $v_{p}$ model at the midpoints of profiles (a) A- $\mathrm{A}^{\prime}$ and (b) $\mathrm{B}-\mathrm{B}^{\prime}$ from Figures 1 and 8 . The solid line represents the thermoelastic conversion from $v_{s}$ (i.e., CUB2.0 TH), and the dashed line is from the empirical scaling relation $d \ln v_{s} / d \ln v_{p}=2.0$, in which AK135 is used as the reference (i.e., CUB2.0_EMP). 

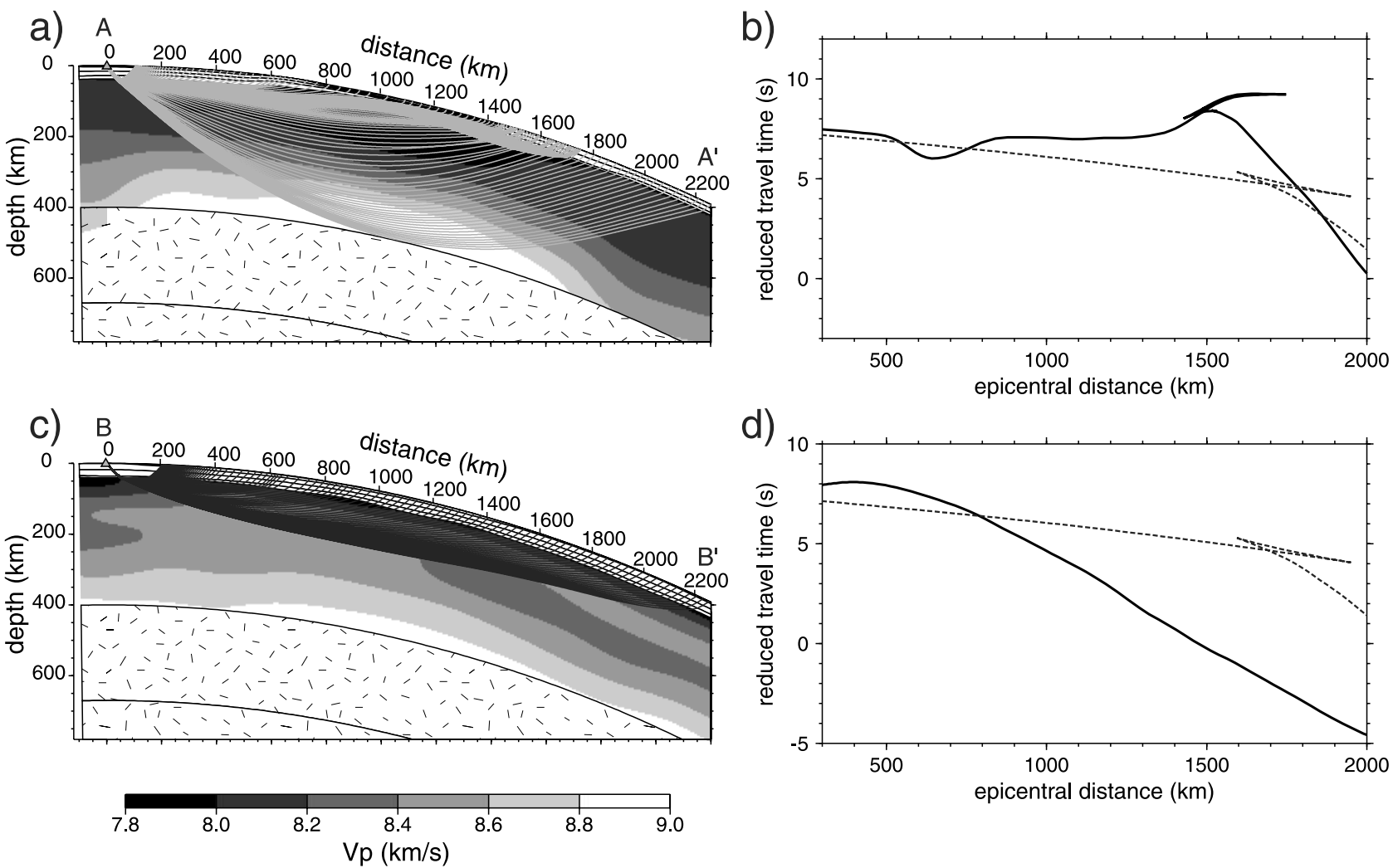

Figure 11. (a and c) $P_{n}$ rays traced through the vertical slices of CUB2.0 TH from Figures 1 and 8. $P$ velocities in the upper mantle underlie the rays. (b and d) The reduced $P_{n}$ travel time curves for each slice (relative to $8.0 \mathrm{~km} \mathrm{~s}^{-1}$ ), shown as solid lines, compared with the $P_{n}$ curves for AK135, shown as dashed lines, demonstrating the complexity of $P_{n}$.
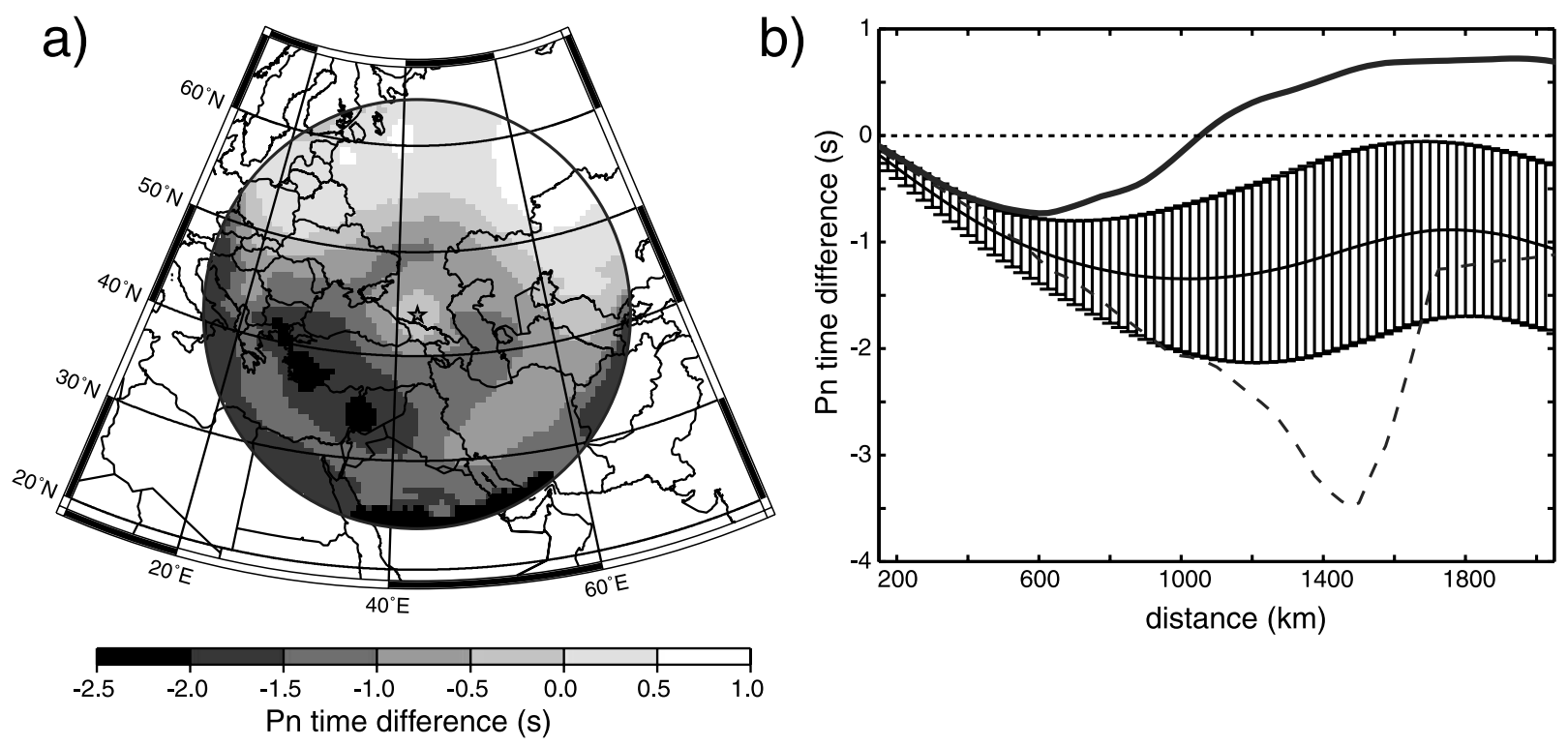

Figure 12. Effect of the $v_{s}$ to $v_{p}$ conversion on $P_{n}$ travel times. (a) Difference between $P_{n}$ travel times from CUB2.0 TH and CUB2.0 EMP, centered on station KIV (Kislovodsk, Russia). Positive values mean CUB2.0 TH travel times are faster than those from CUB2.0 EMP. (b) $P_{n}$ travel time difference between the two models for profile B-B' (solid line) and for profile $A-A^{\prime}$ (dashed line) from Figures 1 and 8. One standard deviation error bars show the geographical average across the region of study (Figure 1). 

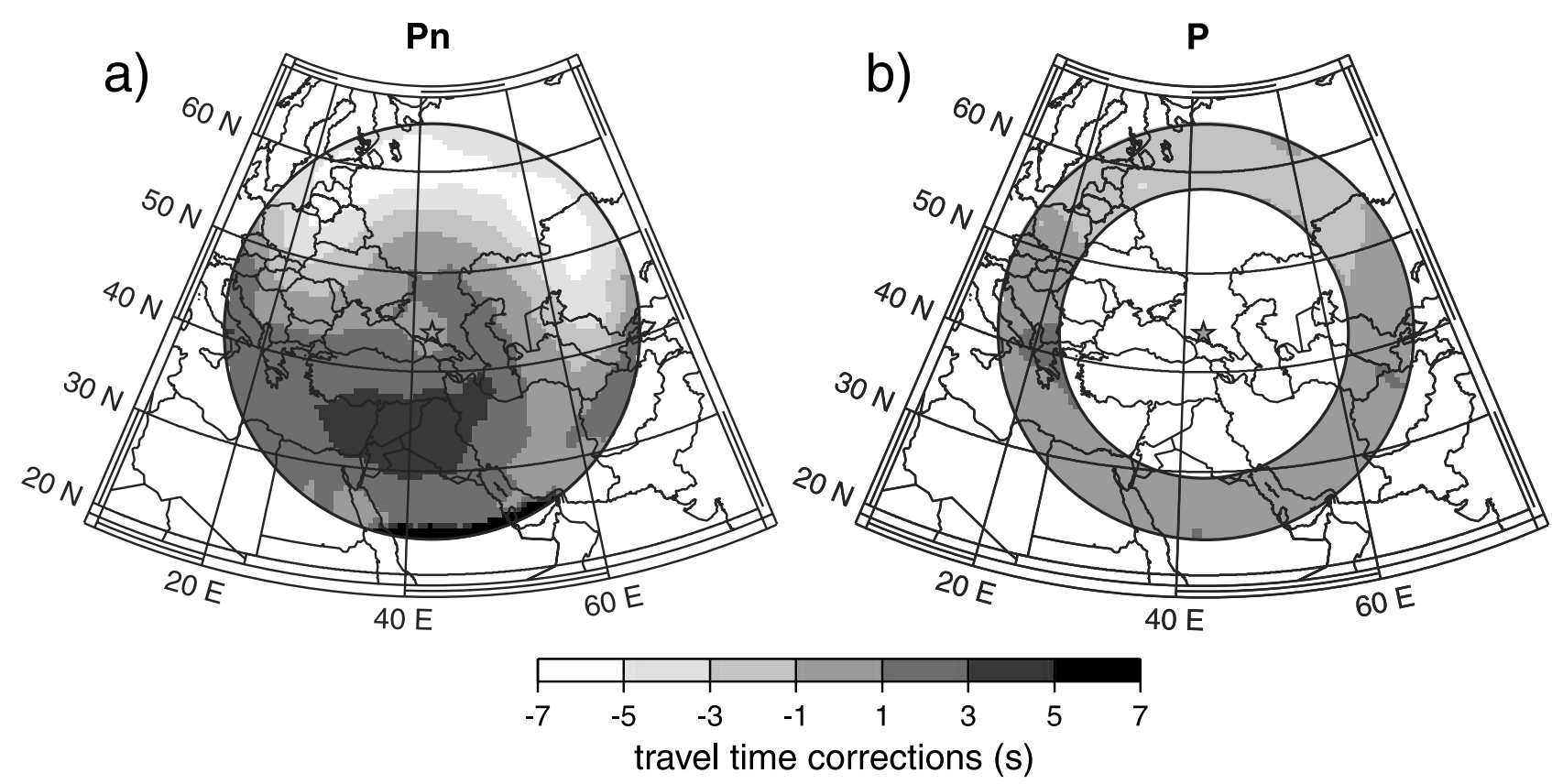

Figure 13. Example of (a) $P_{n}$ and (b) $P$ travel time correction surfaces computed for a surface source for station KIV. The corrections here are relative to the 1D model IASP91 [Kennett and Engdahl, 1991].

between this set of depths. These travel time surfaces depict the predicted travel times from events on a grid of epicentral locations and depths observed at a particular station and are presented relative to the travel time predicted from a 1D model. Figure 13 presents examples of regional station-centered travel time correction surfaces for $P$ and $P_{n}$ computed from CUB2.0_TH relative to the travel times from IASP91. Figure 14 presents examples of event-centered correction surfaces relative to travel times from AK135.

\section{Fit to Regional Travel Times}

[43] The first assessment of the 3D model is to determine how well regional travel times predicted by the $3 \mathrm{D} v_{p}$ models CUB2.0_TH and CUB2.0_EMP fit well-determined regional travel time observations. $\bar{T}$ This test is made possible by the empirical phase path anomaly data set described in section 2 . We compute travel times from each model tested by using the GT locations, depths, and origin times. We will argue that the systematics of misfit establish that the 3D model greatly improves the fit to regional travel times over 1D models and that the thermoelastic conversion from $v_{s}$ is preferable to the empirical scaling relation.

[44] Comparisons are performed both cluster by cluster and aggregated over clusters, segregating the results by event type (e.g., explosions, GT5 earthquakes, or GT10 earthquakes). Examples of cluster-specific comparisons are presented in Figures 14 and 15. In each case we allow an offset to the predicted correction surface to minimize the rms travel time residual. A similar shift was also introduced in the HDC analysis and in the construction of the empirical phase path anomalies discussed in section 2, referred to as "cluster time baseline shifts." These shifts are listed in Table 1, in which the 1D model AK135 and both regional and teleseismic data were used. Using just regional data, they are listed in Tables 3-5 for the 3D model CUB2.0_TH and for the 1D model AK135. Tables 3-5 also provide information about misfit and correlation between the model-predicted travel times and the empirical phase path anomalies. Note that correlation is defined with respect to perturbations relative to AK135. The correlation of AK135 travel times with the empirical phase path anomalies is, therefore, zero because the perturbations are all zero. The variance reductions to the travel times afforded by the 3D model CUB2.0 TH relative to the 1D model AK135 are also presented in Tables $3-5$.

[45] Figure 14 presents examples of cluster-centered travel time correction surfaces produced using CU2.0_TH compared to the empirical path anomalies for $P_{n}$. $\overline{\text { Plots }}$ such as these establish the qualitative agreement between the empirical path anomalies and the model-predicted travel times, at least with respect to the large-scale features of the correction surfaces. More quantitative comparisons are seen in Figure 15, which also demonstrates the effect of phase reidentification using the 3D model. Aggregated comparisons, such as those shown in Figure 16 and the averages presented in Tables 3-5, demonstrate that the model fit to the empirical path anomalies depends strongly on the accuracy of the event locations, with explosions being fit best, followed by GT5 and finally GT10 earthquakes. Figures 15 and 16 display as dashed lines the $\pm 3 \mathrm{~s}$ residual levels to demonstrate that misfits at this level are rare, especially for explosions. In the location assessments below we will therefore use $\pm 3 \mathrm{~s}$ as the cutoff for outlier identification. Residuals whose absolute values are $>3 \mathrm{~s}$ are suspicious measurements or are phases that are particularly difficult to identify.

[46] The rms misfit averaged over the explosion clusters for CUB2.0 TH is $\sim 1.02 \mathrm{~s}$, and misfit averaged over the GT5 and GT10 earthquake clusters averages $1.24 \mathrm{~s}$ and $1.54 \mathrm{~s}$, respectively. These values are to be contrasted with misfit using the 1D model AK135: $1.73 \mathrm{~s}, 1.69 \mathrm{~s}$, and $2.04 \mathrm{~s}$, 

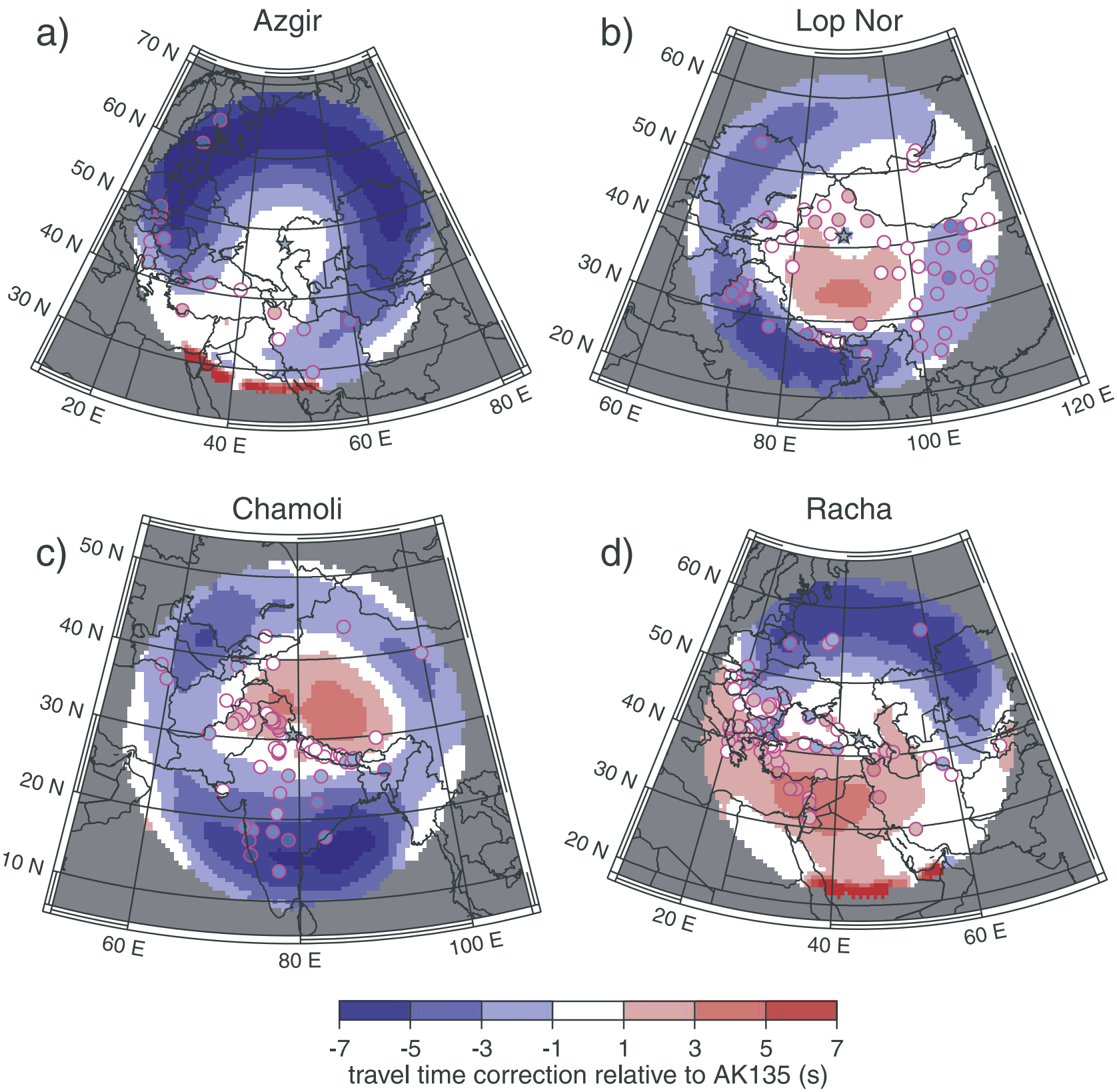

Figure 14. Cluster-centered travel time correction surfaces for four cluster regions. The colored contours are the predictions from the 3D model CUB2.0_ TH referenced to the travel time from the 1D model AK135. The symbols are the empirical phase path anomalies, color coded similarly to the model predictions. The cluster time baseline shift is indicated in Tables 3 and 4. (a and b) Explosions in the Azgir and Lop Nor clusters. (c and d) Earthquakes in the Chamoli and Racha clusters.

respectively. The 3D model therefore delivers a $65 \%$ variance reduction relative to the $1 \mathrm{D}$ model for the explosions and a $\sim 45 \%$ variance reduction for the earthquakes. The fact that the GT level affects the fit to the regional travel times is not surprising but does lend support to the procedure that established the GT level discussed in section 2 .

[47] Tables 3-5 also list the cluster time baseline shifts for CUB2.0_TH and AK135 using the regional empirical phase path anomalies alone (i.e., in contrast to Table 1 , in which teleseismic travel times were used). The cluster time baseline shifts are introduced to compensate for origin time errors in the GT database and to aid in phase identification, but they also act to correct model errors in both the crust and uppermost mantle, particularly beneath the cluster. Tables 3-5 show that, on average, the cluster time baseline shifts are systematically smaller for CUB2.0_TH than for AK135 (explosions, $1.04 \mathrm{~s}$ versus $2.02 \mathrm{~s}$; GT5 earthquakes, $0.76 \mathrm{~s}$ versus $1.42 \mathrm{~s}$; GT10 earthquakes, $0.28 \mathrm{~s}$ versus $1.41 \mathrm{~s})$. In fact, they are smaller for all but two of the clusters which have anomalously small shifts for the 1D model. This is presumably because the $3 \mathrm{D}$ model CUB2.0 TH more accurately models near-cluster structure than the 1D model AK135. (Results are not presented for the Aden or Sahara clusters because there are too few regional data for meaningful statistics.) 

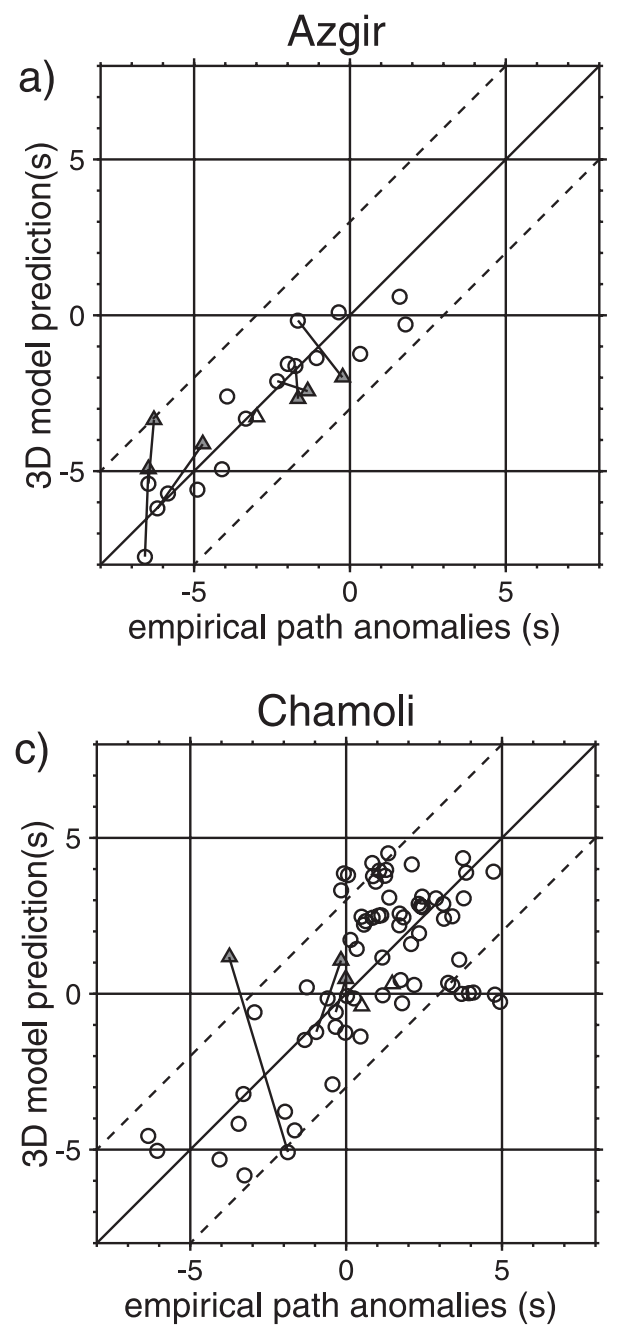
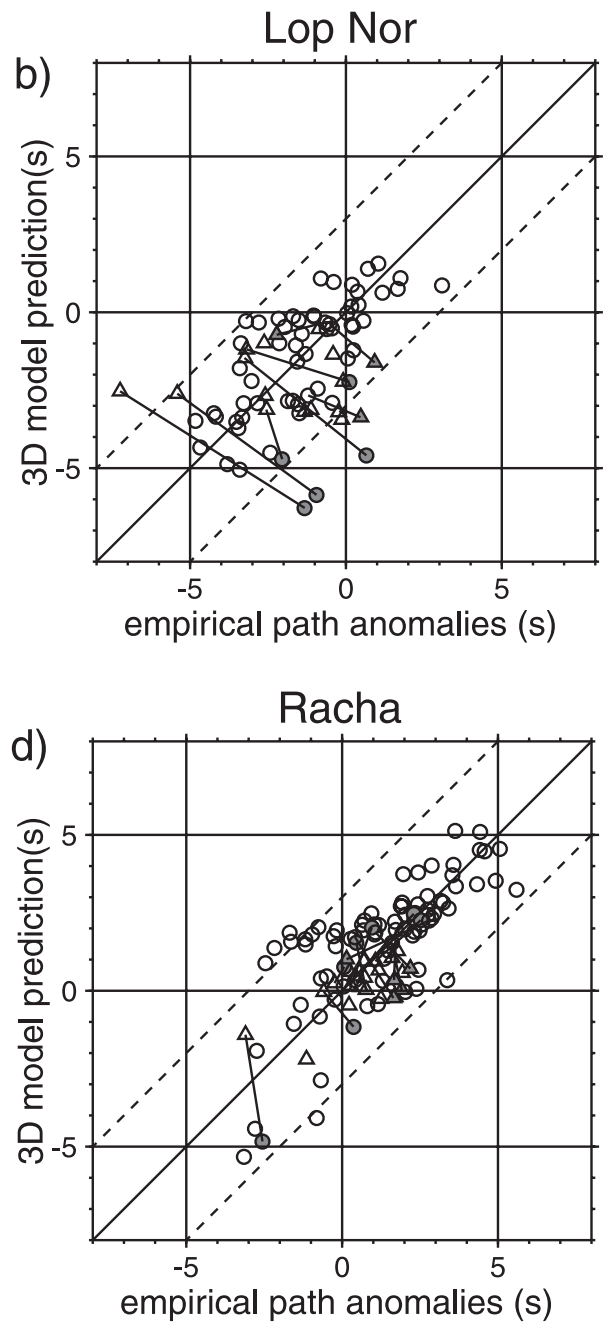

Figure 15. Comparison between the $P$ and $P_{n}$ travel times predicted by the 3D model CUB2.0_TH and by the empirical phase path anomalies for the four event clusters shown in Figure 14: (a) Azgir; (b) Lop Nor; (c) Chamoli; and (d) Racha. The empirical path anomalies are on the horizontal axis, paired with the model predictions on the vertical axis. Circles are $P_{n}$ and triangles are $P$. Phases have been reidentified using the 3D model; bars link phases originally identified with the 1D model AK135 (shaded) to the reidentified phases (unshaded). The cluster time baseline shifts listed in Tables 3 and 4 have been applied. The dashed lines mark the location of \pm 3 s residuals.

[48] Because the cluster time baseline shifts may obscure some problems with the model, it is also important to perform travel time comparisons without the shifts. Figure 17 compares the empirical $P$ and $P_{n}$ path anomalies with the travel times predicted by a number of models (1D models AK135 and PREM; 3D models CU2.0_TH, CU2.0_EMP, and AK135 + CRUST5.1 + S20A_TH) as a function of epicentral distance. The model ĀK135 + CRUST5.1 + S20A_TH is a $v_{p}$ model of the crust and mantle, constructed by placing CRUST5.1 [Mooney et al., 1998] on top of the $v_{p}$ model converted from the 3D mantle $v_{s}$ model S20A [Ekström and Dziewonski, 1998]. The model S20A was, in fact, developed as an aspherical perturbation to PREM, but because PREM was not developed to fit regional travel times, we replace it with AK135 as the spherical reference for this model. Finally, we use the thermoelastic conversion from $v_{s}$ to $v_{p}$ to compute the $v_{p}$ part of the mantle model; hence the suffix on the name AK135 + CRUST5.1 + S20A_TH.
[49] Figures $17 \mathrm{a}-17 \mathrm{e}$ show residuals for every empirical path anomaly in the database. These residuals are averaged in distance bins and broken into a vertical offset (or bias); the standard deviation around the offset is shown in Figures $17 \mathrm{f}$ and $17 \mathrm{~g}$. We divide the comparison in this way because it is possible for a model to fit the geographical pattern of travel time residuals well but be systematically biased. The overall rms residual would therefore be large, but that alone would provide little insight into the reason behind the large residuals.

[50] Figures $17 \mathrm{f}$ and $17 \mathrm{~g}$ demonstrate that the $1 \mathrm{D}$ model AK135, which was constructed to fit regional travel times on average, fits the empirical path anomalies better than PREM, which displays a bias of $\sim 4 \mathrm{~s}$ at distances $<1500 \mathrm{~km}$. This is largely due to thin crust in PREM ( $\sim 20 \mathrm{~km}$ after the ocean was removed for continental application). The pattern of bias for CUB2.0_EMP reflects the bias in AK135, probably because of the reliance of the empirical $v_{s}$ to $v_{p}$ conversion on AK135. The travel times from the two 3D models that have been converted to $v_{p}$ with 
Table 3. Fit to Empirical Phase Path Anomalies for Explosions

\begin{tabular}{|c|c|c|c|c|c|c|c|c|}
\hline \multirow[b]{2}{*}{ Cluster } & \multirow[b]{2}{*}{ Name } & \multirow[b]{2}{*}{$N^{\mathrm{a}}$} & \multicolumn{4}{|c|}{ CUB2.0_TH } & \multicolumn{2}{|c|}{ AK135 } \\
\hline & & & $\begin{array}{c}\text { Variance } \\
\text { Reduction, }{ }^{\mathrm{b}} \%\end{array}$ & $\mathrm{rms}^{\mathrm{c}} \mathrm{s}$ & Correlation $^{\mathrm{d}}$ & $\Delta t_{0},{ }^{\mathrm{e}} \mathrm{s}$ & $\mathrm{rms},{ }^{\mathrm{c}} \mathrm{s}$ & $\Delta t_{0},{ }^{\mathrm{e}} \mathrm{s}$ \\
\hline 1 & Azgir & 18 & 87 & 0.94 & 0.88 & 1.17 & 2.58 & 1.99 \\
\hline 2 & Balapan & 39 & 50 & 0.98 & 0.74 & 1.69 & 1.38 & 2.29 \\
\hline 3 & Degelen & 14 & 57 & 0.98 & 0.67 & 0.54 & 1.49 & 1.61 \\
\hline 4 & Lop Nor & 71 & 19 & 1.50 & 0.63 & 1.66 & 1.67 & 1.29 \\
\hline 5 & Novaya & 14 & 79 & 0.70 & 0.83 & 0.15 & 1.53 & 2.90 \\
\hline Average of absolute values & & & 65 & 1.02 & 0.75 & 1.04 & 1.73 & 2.02 \\
\hline
\end{tabular}

the thermoelastic conversion (CUB2.0 TH, AK135 + CRUST5.1 + S20A) are much less biase $\bar{d}$. This is one of the reasons for our preference for the thermoelastic $v_{s}$ to $v_{p}$ conversion. We will therefore not consider CUB2.0_EMP in the location exercises below.

[51] The fit to the geographical pattern of empirical phase path anomalies is revealed in the standard deviation shown in Figure $17 \mathrm{~g}$. The 3D models all fit better than the 1D models. CUB2.0_TH has only a slightly smaller standard deviation than does CUB2.0_EMP, but both fit the pattern of empirical phase path anomalies somewhat better than AK135 + CRUST5.1 + S20A. This is promising because CUB2.0_TH was built by perturbing AK135 + CRUST5.1 + S20A. This perturbation was accomplished by introducing many regional group speed measurements in an attempt to improve lateral and, more importantly, vertical resolution in the resulting model (e.g., Figure 7). There was no guarantee that this procedure would produce a $v_{p}$ model that would improve the fit to regional $P$ phases, but these results establish that it has. This points the way to future advancements in $v_{s}$ models providing further improvements in regional location capabilities.

\section{Location Method}

[52] We developed a grid search location method for use in the second assessment of the 3D model. In addition to the three principal unknowns, origin time $\left(t_{0}\right)$, depth $(z)$, and epicentral location $(x, y)$, we consider phase identification to be unknown. We fix the depth because it trades off with origin time, and fixing it has little effect on the epicentral location. To simplify the inversion, we reidentify phases only at the grid center rather than at each grid node separately and use only $P_{n}$ and $P$ data observed between $\sim 3^{\circ}$ and $20^{\circ}$. The use of $S_{n}$ and $S$ travel times would improve the locations, particularly for locations with few reporting stations. The quality and distribution of reported regional $S$ phases, however, are much more variable than $P$ phases, and their use would make the results more difficult to interpret. These simplifications result in much more stable location results, but the location method differs substantially from procedures that are used to construct global catalogs. Thus our reports of location capabilities are probably more meaningful in a relative sense (e.g., location error with the $3 \mathrm{D}$ model relative to the $1 \mathrm{D}$ model) than in an absolute sense. The 3D model that is tested here is CUB2.0_TH, and the 1D model is AK135.

[53] The location procedure progresses in five steps.

[54] (1) The depth $z$ is fixed to the value in the GT location database.

[55] (2) The grid is chosen with the grid center at the EHB location [Engdahl et al., 1998] for earthquakes and at the preliminary determination of epicenters (PDE) location

Table 4. Fit to Empirical Phase Path Anomalies for GT5 Earthquakes

\begin{tabular}{|c|c|c|c|c|c|c|c|c|}
\hline \multirow[b]{2}{*}{ Cluster } & \multirow[b]{2}{*}{ Name } & \multirow[b]{2}{*}{$N^{\mathrm{a}}$} & \multicolumn{4}{|c|}{ CUB2.0_TH } & \multicolumn{2}{|c|}{ AK135 } \\
\hline & & & Variance Reduction, ${ }^{\mathrm{b}} \%$ & $\mathrm{rms},{ }^{\mathrm{c}} \mathrm{s}$ & Correlation $^{\mathrm{d}}$ & $\Delta t_{0},{ }^{\mathrm{e}} \mathrm{s}$ & $\mathrm{rms},{ }^{\mathrm{c}} \mathrm{s}$ & $\Delta t_{0},{ }^{\mathrm{e}} \mathrm{s}$ \\
\hline 7 & Adana & 62 & 15 & 1.08 & 0.50 & -1.76 & 1.17 & -2.57 \\
\hline 8 & Bhuj & 47 & 54 & 1.37 & 0.77 & -0.78 & 2.01 & 0.48 \\
\hline 9 & Chamoli & 73 & 23 & 2.09 & 0.65 & -0.49 & 2.39 & -1.13 \\
\hline 10 & Duzce & 99 & 20 & 1.32 & 0.53 & -0.14 & 1.48 & -0.97 \\
\hline 11 & Erzin & 16 & 68 & 1.20 & 0.77 & -1.78 & 2.11 & -2.55 \\
\hline 12 & Garm & 42 & 78 & 1.20 & 0.87 & -0.89 & 2.56 & -1.54 \\
\hline 13 & Hoceima & 49 & 19 & 0.76 & 0.43 & 0.67 & 0.84 & -0.23 \\
\hline 14 & Izmit & 131 & 5 & 1.05 & 0.57 & ${ }_{-0.10}$ & 1.07 & -1.00 \\
\hline 15 & Koyna & 15 & 61 & 0.99 & 0.85 & -0.94 & 1.58 & 2.51 \\
\hline 16 & Racha & 101 & 45 & 1.40 & 0.72 & -0.15 & 1.88 & -1.49 \\
\hline 17 & Siberia & 32 & 46 & 1.13 & 0.69 & -0.65 & 1.54 & -1.10 \\
\hline Average & & & 46 & 1.24 & 0.67 & 0.76 & 1.69 & 1.42 \\
\hline
\end{tabular}

${ }^{\mathrm{a}}$ Number of measurements in the cluster.

${ }^{\mathrm{b}}$ Relative to AK135.

${ }^{\mathrm{c}}$ Misfit between observed and predicted travel times.

${ }^{\mathrm{d}}$ Correlation between observed and predicted travel times.

${ }^{\mathrm{e}}$ Cluster time baseline shift applied to regional data alone. 
Table 5. Fit to Empirical Phase Path Anomalies for GT10 Earthquakes

\begin{tabular}{|c|c|c|c|c|c|c|c|c|}
\hline \multirow[b]{2}{*}{ Cluster } & \multirow[b]{2}{*}{ Name } & \multirow[b]{2}{*}{$N^{\mathrm{a}}$} & \multicolumn{4}{|c|}{ CUB2.0_TH } & \multicolumn{2}{|c|}{ AK135 } \\
\hline & & & Variance Reduction, ${ }^{\mathrm{b}} \%$ & $\mathrm{rms}^{\mathrm{c}}{ }^{\mathrm{s}} \mathrm{s}$ & Correlation $^{\mathrm{d}}$ & $\Delta t_{0}^{\mathrm{e}} \mathrm{s}$ & $\mathrm{rms},{ }^{\mathrm{c}} \mathrm{s}$ & $\Delta t_{0},{ }^{\mathrm{e}} \mathrm{s}$ \\
\hline 19 & Aqaba & 80 & 21 & 1.61 & 0.31 & -0.11 & 1.81 & -0.26 \\
\hline 20 & Gubal & 17 & 69 & 1.06 & 0.77 & 0.09 & 1.89 & -1.13 \\
\hline 21 & Jiashi & 33 & 50 & 2.06 & 0.77 & 0.40 & 2.91 & -1.66 \\
\hline 22 & Spitak & 30 & 50 & 1.23 & 0.84 & -0.08 & 1.74 & -1.40 \\
\hline 23 & Tabas & 39 & 11 & 1.74 & 0.37 & -0.71 & 1.84 & -2.58 \\
\hline Average & & & 43 & 1.54 & 0.61 & 0.28 & 2.04 & 1.41 \\
\hline
\end{tabular}

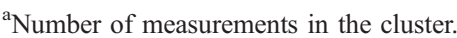

${ }^{\mathrm{b}}$ Relative to AK135.

${ }^{\mathrm{c}}$ Misfit between observed and predicted travel times.

${ }^{\mathrm{d}}$ Correlation between observed and predicted travel times.

${ }^{\mathrm{e}}$ Cluster time baseline shift applied to regional data alone.

for explosions, and nodes are located every $1 \mathrm{~km}$ to create a $50 \times 50 \mathrm{~km}$ grid. The PDE location is chosen for the grid center for explosions because the EHB location for explosions is commonly of GT0-2 quality, which would create an asymmetry between earthquakes and explosions. The EHB and PDE locations are probably more accurately characterized as GT10-GT15.
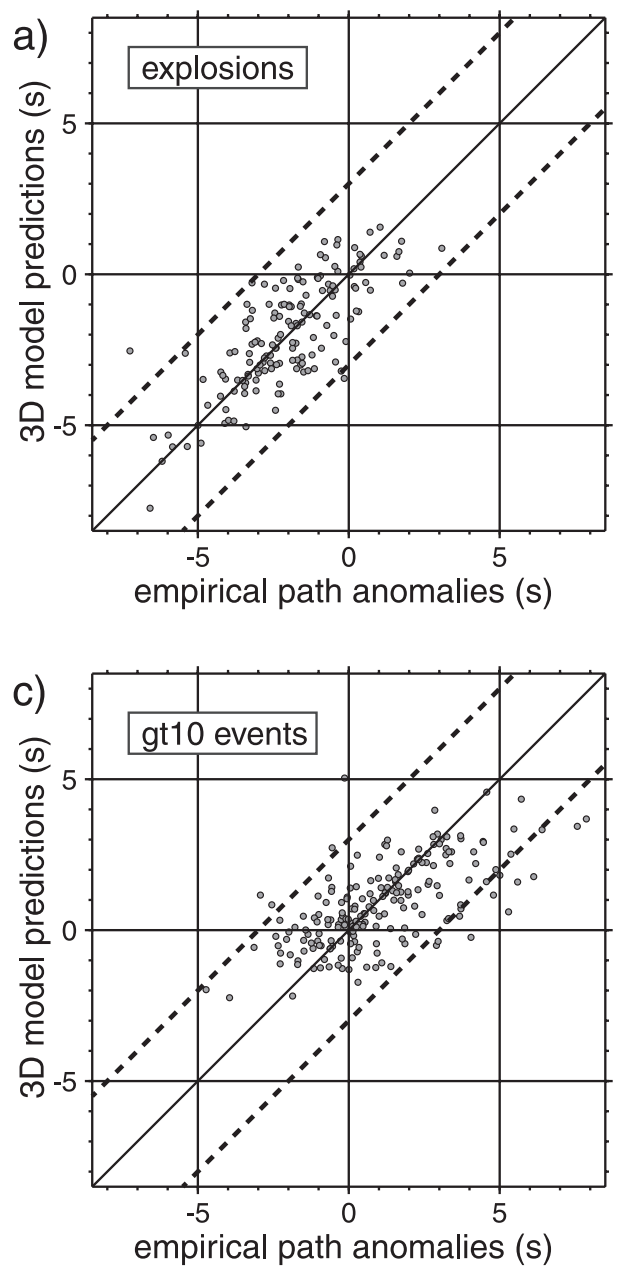

[56] (3) With a hypothesized epicenter at the grid center, each travel time is identified as either $P$ or $P_{n}$, and the origin time is shifted (relative to an input estimate) to give the smallest overall rms residual.

[57] (4) Residuals larger than \pm 3 s using the $3 \mathrm{D}$ model are considered to be outliers and are rejected. The $3 \mathrm{~s}$ criterion is based on fits to the empirical phase path
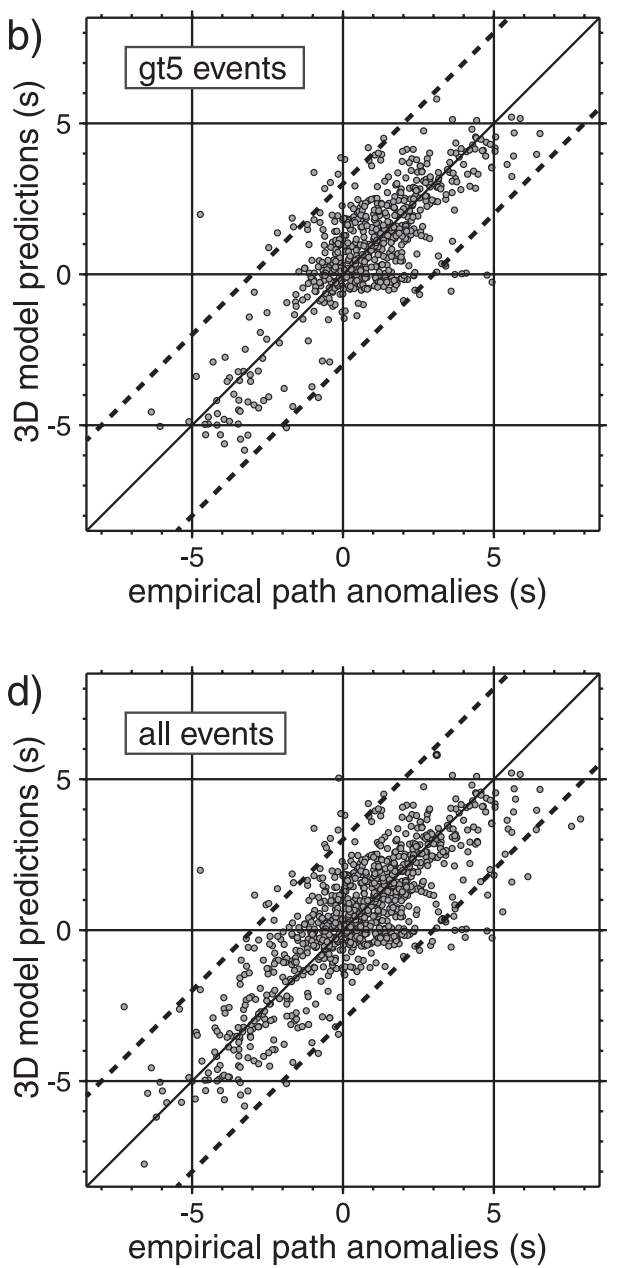

Figure 16. Overall comparison between the $P$ and $P_{n}$ travel times predicted by the 3D model CUB2.0 TH and the empirical phase path anomalies for (a) explosions; (b) GT5 events; (c) GT10 events; and (d) all events. The cluster time baseline shifts listed in Tables 3-5 have been applied, and misfit statistics are also listed in these tables. 

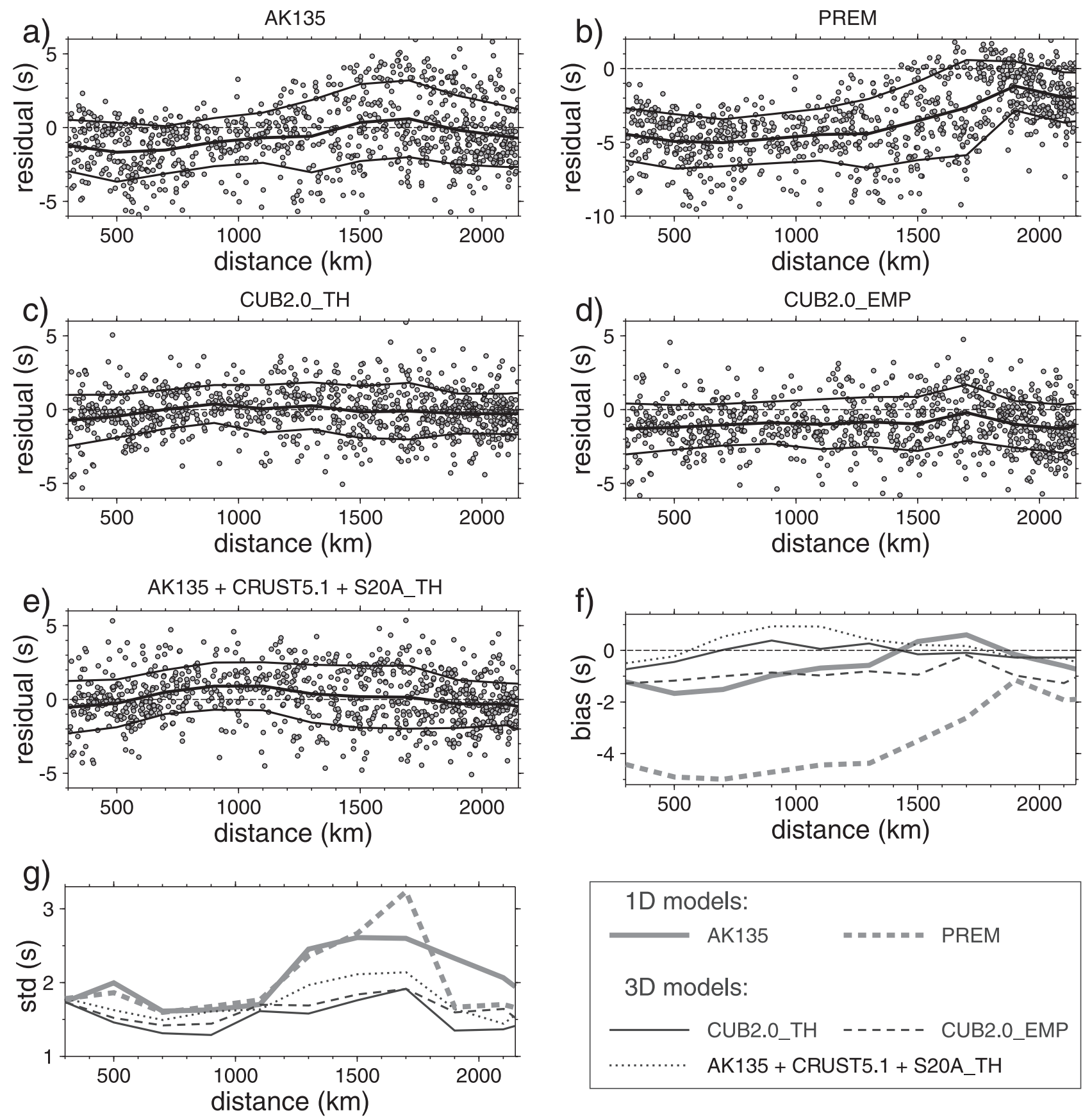

Figure 17. (a-e) Residual between the empirical phase path anomalies for $P_{n}$ and $P$ and predictions from a number of models, plotted versus epicentral distance. The running average (bias) and standard deviation are shown as the solid lines. Cluster time baseline shifts have not been applied. (f-g) Running residual bias and standard deviation shown for the various models.

anomalies (e.g., Figure 16). It is at about the $3 \sigma$ level for explosions and $2 \sigma$ for earthquakes. The details of this choice have little effect on the overall statistics because the number of observations that are rejected is small. In principal, this procedure could be performed separately at each grid node, but this produces different data sets for each model, which would complicate the interpretation of the results. We also believe that the $3 \mathrm{D}$ model accurately identifies erroneous measurements.

[58] (5) Hypothetical epicenters are moved to each grid node, and the estimated event location is identified with the grid node that produces the minimum misfit to the observed travel times in the groomed arrival time data set.

[59] An example of the location grid for an explosion on the Lop Nor test site is shown in Figure 18.

\section{Regional Location Experiment}

[60] The location experiment is performed using only $P$ and $P_{n}$ travel times from the groomed arrival time data set, observed within $20^{\circ}$ of the epicenter. The figure of merit is the ability to locate those events in the GT data set with a 


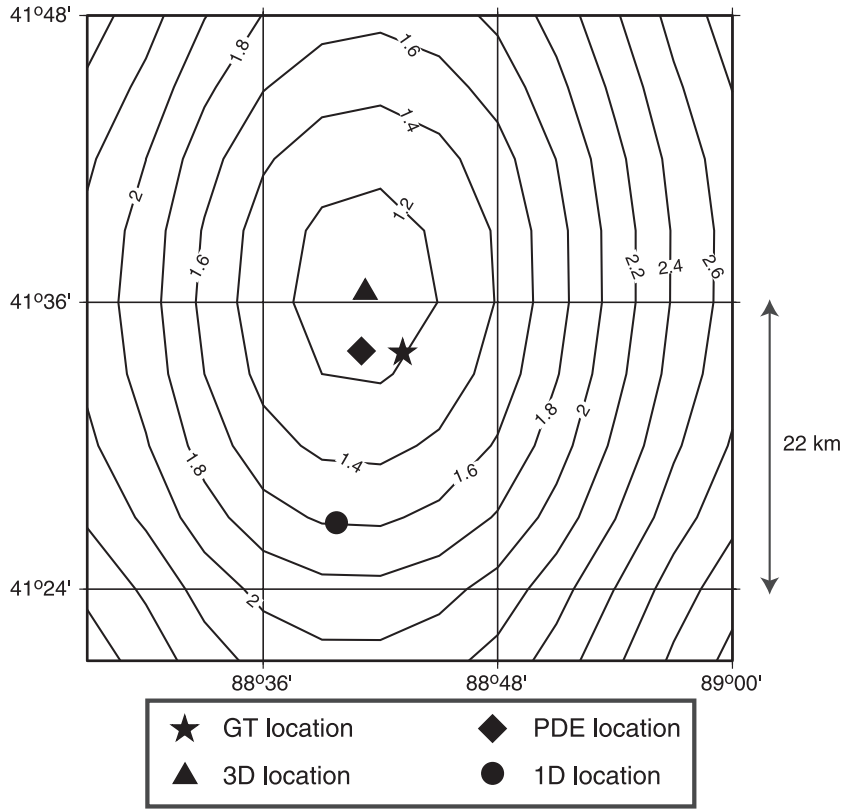

Figure 18. Contours of rms misfit using the 3D model CUB2.0 TH for a grid of hypothesized epicenters for an explosion at the Lop Nor test site (26 May 1990; 54 reporting stations). Units are in s. The GT1-2 location is indicated with a star, the best fit locations using the 3D model CUB2.0 TH and the 1D model AK135 are shown with a triangle and a circle, respectively, and the PDE location is shown with a diamond.

location accuracy of GT5 or better. We compare the location capabilities of the 3D model CUB2.0_TH to that of the 1D model AK135. Examples of locations using these models are shown in Figure 19 for the Lop Nor and Racha clusters. Qualitatively, it can be seen that the 3D model improves the agreement with the GT locations and reduces systematic bias.

[61] The geometry of the network of reporting stations plays a major role in location accuracy. Figure 20 presents examples of how location error varies with the number of stations and open azimuth. These results are determined by estimating locations repeatedly using randomly chosen subsets of the reported data in the groomed arrival time data set with a specified number of recording stations. The location systematics for the 3D model are clear and reasonable: As the number of stations decreases and open azimuth increases, the location accuracy degrades. We aim, however, for the statistics on location accuracy to reflect the capabilities of the model rather than the vagaries of station geometry. It is therefore important to limit the role that variations in network geometry between different event regions play on the reported locations. For this reason the location statistics reported in Tables 6-8 are only for the GT events in which the regional phases have an open azimuth of $<180^{\circ}$. This reduces the GT data set by $>60 \%$, from 989 to 366 events. The number of explosions is most severely reduced, from 312 to 38 events, but the number of events remains high enough to draw statistically meaningful conclusions.

[62] Using the 3D model CUB1.0 TH, the location accuracy improves systematically with confidence in the GT location: $5.1 \mathrm{~km}, 7.2 \mathrm{~km}$, and $12.3 \mathrm{~km}$ errors for explosions (GT0-GT2), GT5 earthquakes, and GT10 earth- quakes, respectively. By the following reasoning, we believe that these results are consistent with an intrinsic location accuracy of $\sim 5 \mathrm{~km}$ for the 3D model. Assuming that the regional location errors and the reported GT confidence levels are uncorrelated, we would expect a location error of about $\left(5^{2}+5^{2}\right)^{1 / 2} \mathrm{~km} \sim 7 \mathrm{~km}$ for GT5 events if the intrinsic location error is itself $5 \mathrm{~km}$ and $\left(10^{2}+5^{2}\right)^{1 / 2} \mathrm{~km} \sim 12 \mathrm{~km}$ for GT10 events. These expectations are very similar to the results of our tests and give us further confidence in the GT levels reported in Table 1.

[63] Location errors for the 1D model do not trend as simply with GT levels. Location errors are $14.1 \mathrm{~km}, 10.9 \mathrm{~km}$, and $13.3 \mathrm{~km}$ for explosions, GT5 earthquakes, and GT10 earthquakes, respectively. The location error for explosions is elevated by the difficulties that the 1D model experiences in locating the Azgir events. The reason is the nature of the 3D structure near Azgir: fast continental platforms to the north and slow tectonic regions to the south. The 3D model corrects for this large-scale variability very well, but the 1D model produces systematically biased locations similar to its performance at Racha (Figure 19d). It is, nevertheless, reasonable to conclude that the $1 \mathrm{D}$ model possesses an average intrinsic location accuracy of $\sim 10 \mathrm{~km}$, from which we would expect estimated location errors of $\sim 10$, $\sim 11$, and $\sim 14 \mathrm{~km}$ for explosions, GT5 earthquakes, and GT10 earthquakes, respectively. This accuracy is much more geographically variable than for the $3 \mathrm{D}$ model, however.

[64] These estimates of intrinsic location accuracies $(5 \mathrm{~km}$ for the 3D model, $10 \mathrm{~km}$ for the $1 \mathrm{D}$ model) have been determined for relatively large events, for which a large number of regional phases were available. It is important in a number of applications, particularly in nuclear monitoring, to understand how location accuracy degrades as the network of recording stations becomes increasingly sparse. Figure 21 addresses this question by considering location accuracy as a function of random subsets of the reported stations. The approach is similar to that taken in Figure 20, but here we have aggregated the results over different types of events: explosions in Figure 21a and GT5 events in Figure 21b. The averages and standard deviations of the distributions of locations are presented as a function of the number of stations, with the constraint that open azimuth remains $<180^{\circ}$. Note that the locations of the explosions using the 3D model degrade from $\sim 5 \mathrm{~km}$ using a large number of stations to $\sim 8 \mathrm{~km}$ on average for five reported stations. GT5 earthquake locations using the 3D model similarly degrade from averages of $\sim 7 \mathrm{~km}$ to $11 \mathrm{~km}$. Figures $21 \mathrm{a}$ and $21 \mathrm{~b}$ also show that (1) the average location error grows as the number of stations decreases, with degradation setting on at about 10 stations, (2) the mean and standard deviation of the distributions are smaller for the 3D model than for the 1D model, and (3) the mean and standard deviation are smaller for explosions than for GT5 earthquakes.

[65] What is not shown in Figures 21a and 21b is that the distributions of location error for the two models are highly correlated. Therefore, even though the location error distributions for the two models for the GT5 earthquakes overlap appreciably, the $3 \mathrm{D}$ model location is better than the 1D model location in no less than $70 \%$ of the cases considered. For the GT5 earthquakes this number remains approximately constant with the number of reporting stations. For the explosions, however, it degrades from $>90 \%$ 

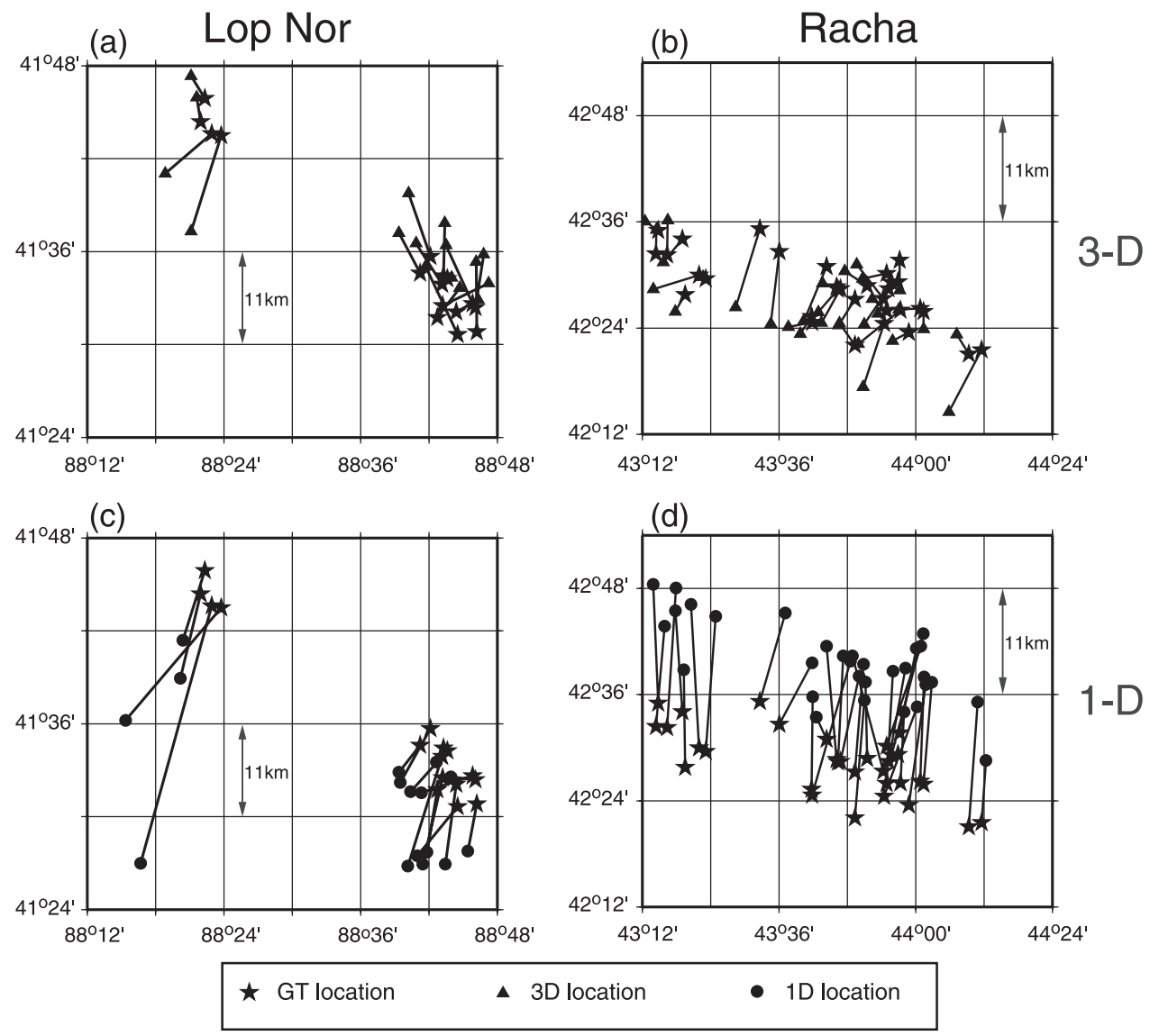

Figure 19. Mislocation vectors from two event clusters for (left) explosions on the Lop Nor test site and (right) earthquakes near Racha, Georgia. ( $\mathrm{a}$ and b) 3D model (CUB2.0 TH) locations. (c and d) 1D model (AK135) locations. Stars mark GT locations, and triangles and circles are 3D and 1D model locations, respectively.

for large numbers of stations used to $\sim 75-80 \%$ for sparse networks containing fewer than 10 regional stations.

\section{Discussion}

[66] The assessments reported in sections 5 and 7 yield a number of general lessons that we discuss further here.

\subsection{GT Databases}

[67] Databases of earthquake and explosion locations with high accuracy and quantified uncertainties (ground truth databases) provide valuable information needed to test Earth models and to determine seismic location capabilities. Such databases are very difficult to assemble, however, as they require substantial efforts to validate. The Hypocen-
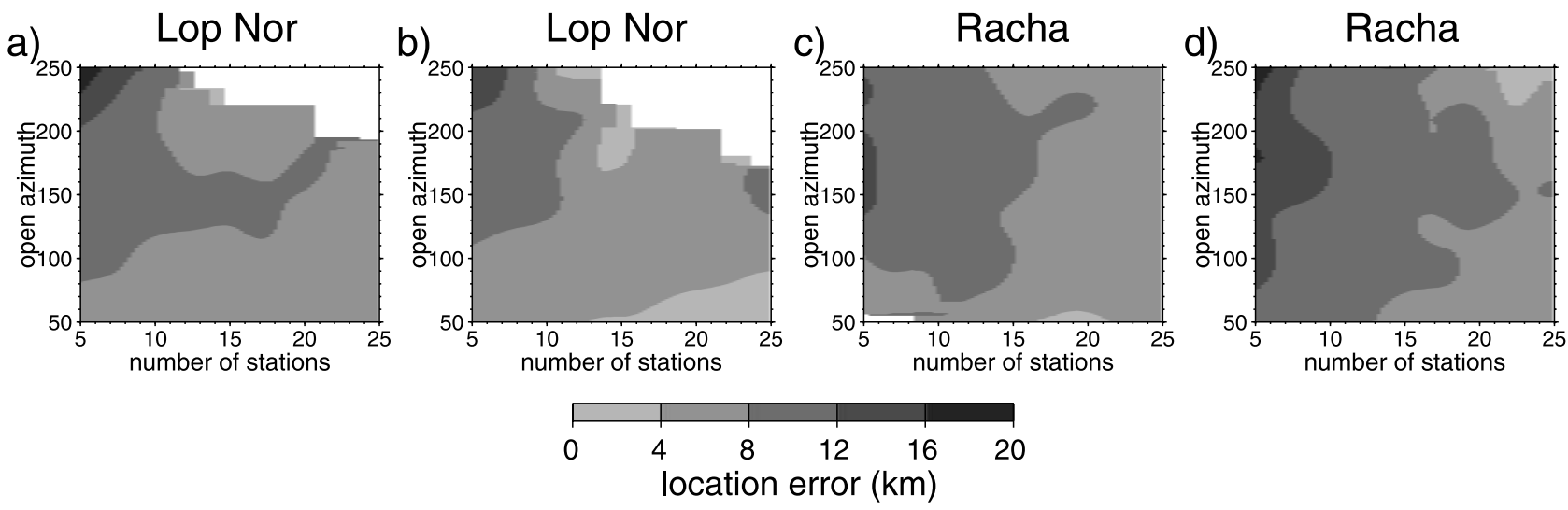

Figure 20. Mislocation using the 3D model CUB2.0 TH, presented as a function of number of stations and open azimuth, determined by randomly choosing subsets of the reported travel times for four events: (a) Lop Nor, 26 May 1990; (b) Lop Nor, 25 September 1992; (c) Racha, 3 May 1991; (d) Racha, 4 July 1991. 
Table 6. Location Results for Nuclear Explosions

\begin{tabular}{|c|c|c|c|c|c|c|c|}
\hline \multirow[b]{2}{*}{ Cluster } & \multirow[b]{2}{*}{ Name } & \multirow[b]{2}{*}{ Events $^{\mathrm{a}}$} & \multirow[b]{2}{*}{ Stations $^{\mathrm{b}}$} & \multicolumn{2}{|c|}{ CUB2.0_TH } & \multicolumn{2}{|c|}{ AK135 } \\
\hline & & & & $\begin{array}{c}\text { Error, } \\
\text { km }\end{array}$ & $\begin{array}{c}\mathrm{rms}^{\mathrm{d}}{ }^{\mathrm{d}} \\
\end{array}$ & $\begin{array}{c}\text { Error, } \\
\text { km }\end{array}$ & $\begin{array}{c}\mathrm{rms}^{\mathrm{d}}{ }^{\mathrm{S}} \\
\end{array}$ \\
\hline 1 & Azgir & 6 & 19 & 4.2 & 1.08 & 24.0 & 1.49 \\
\hline 2 & Balapan & 10 & 25 & 3.9 & 1.10 & 11.2 & 1.22 \\
\hline 3 & Degelen & 3 & 18 & 3.1 & 1.01 & 12.0 & 1.36 \\
\hline 4 & Lop Nor & 16 & 45 & 6.1 & 1.22 & 9.6 & 1.49 \\
\hline 5 & Novaya & 3 & 15 & 8.0 & 1.03 & 13.6 & 1.57 \\
\hline Overall $^{\mathrm{e}}$ & & 38 & 24 & 5.1 & 1.09 & 14.1 & 1.43 \\
\hline \multicolumn{8}{|c|}{$\begin{array}{l}{ }^{\mathrm{a}} \text { Number of events with open azimuth }<180^{\circ} \text { and } \geq 5 \text { stations. } \\
{ }^{\mathrm{b}} \text { Median number of stations. } \\
{ }^{\mathrm{c}} \text { Average distance from estimated to GT location. }\end{array}$} \\
\hline
\end{tabular}

troidal Decomposition method of multiple event location, in particular, is well suited to the requirements of ground truth validation exercises. The empirical phase path anomalies that can be constructed from clusters of events provide important ancillary information about the capabilities of Earth models. Certainly, other databases of locations and regional travel times exist in addition to those that we have applied here, for example, there are other nuclear explosions across Eurasia that we have not used [e.g., Murphy et al., 2001]. Although these databases also provide information relevant to testing regional travel time models, our reliance on event clusters has the advantage of producing multiple arrivals for every path, which allows outlier rejection and the establishment of an uncertainty for every reported travel time.

\subsection{Role of a Global 3D Earth Model in Improving Regional Locations}

[68] The 3D models tested here (CUB2.0, S20A) are, in essence, $v_{s}$ models of the upper mantle that have been derived largely from information about surface wave dispersion. Surface waves possess the salutary characteristic that they sample the entire Earth, and over large regions, data coverage is dense and relatively homogeneous. Another advantage is that broadband surface wave dispersion constrains the vertical velocity gradient in the upper mantle. The vertical gradient controls ray turning depths which, in turn,

Table 7. Location Results for GT5 Earthquakes

\begin{tabular}{|c|c|c|c|c|c|c|c|}
\hline \multirow[b]{2}{*}{ Cluster } & \multirow[b]{2}{*}{ Name } & \multirow[b]{2}{*}{ Events $^{\mathrm{a}}$} & \multirow[b]{2}{*}{ Stations $^{\mathrm{b}}$} & \multicolumn{2}{|c|}{ CUB2.0_TH } & \multicolumn{2}{|c|}{ AK 135} \\
\hline & & & & $\begin{array}{c}\text { Error, } \\
\text { km }\end{array}$ & $\begin{array}{c}\mathrm{rms}^{\mathrm{d}}{ }^{\mathrm{s}} \\
\end{array}$ & $\begin{array}{c}\text { Error, } \\
\text { km }\end{array}$ & $\begin{array}{c}\mathrm{rms}^{\mathrm{d}}{ }^{\mathrm{S}} \\
\end{array}$ \\
\hline 7 & Adana & 19 & 23 & 8.8 & 1.04 & 8.1 & 1.17 \\
\hline 8 & Bhuj & 4 & 15 & 11.5 & 1.00 & 8.5 & 1.42 \\
\hline 9 & Chamoli & 50 & 17 & 10.8 & 1.20 & 20.8 & 1.54 \\
\hline 10 & Duzce & 21 & 45 & 7.3 & 1.23 & 6.6 & 1.33 \\
\hline 11 & Erzin & 8 & 33 & 6.0 & 1.29 & 9.5 & 1.61 \\
\hline 12 & Garm & 26 & 21 & 5.2 & 1.12 & 9.7 & 2.17 \\
\hline 13 & Hoceima & 21 & 26 & 4.4 & 0.90 & 7.5 & 0.86 \\
\hline 14 & Izmit & 8 & 116 & 5.1 & 1.07 & 5.3 & 1.10 \\
\hline 15 & Koyna & 8 & 10 & 5.5 & 1.13 & 10.7 & 1.23 \\
\hline 16 & Racha & 34 & 20 & 8.2 & 1.15 & 21.8 & 1.43 \\
\hline 17 & Siberia & 8 & 33 & 6.3 & 1.13 & 11.0 & 1.31 \\
\hline Overall & & 207 & 32 & 7.2 & 1.12 & 10.9 & 1.38 \\
\hline
\end{tabular}

${ }^{\mathrm{a}}$ Number of events with open azimuth $<180^{\circ}$ and $\geq 5$ stations

${ }^{\mathrm{b}}$ Median number of stations.

${ }^{\mathrm{c}}$ Average distance from estimated to GT location.

${ }^{\mathrm{d}} \mathrm{Rms}$ difference between observed and predicted travel times.

${ }^{\mathrm{e}}$ Total or average of cluster values.
Table 8. Location Results for GT10 Earthquakes

\begin{tabular}{|c|c|c|c|c|c|c|c|}
\hline \multirow[b]{2}{*}{ Cluster } & \multirow[b]{2}{*}{ Name } & \multirow[b]{2}{*}{ Events $^{\mathrm{a}}$} & \multirow[b]{2}{*}{ Stations $^{\mathrm{b}}$} & \multicolumn{2}{|c|}{ CUB2.0_TH } & \multicolumn{2}{|c|}{ AK135 } \\
\hline & & & & Error, ${ }^{\mathrm{c}} \mathrm{km}$ & $\mathrm{rms},{ }^{\mathrm{d}} \mathrm{s}$ & Error, ${ }^{\mathrm{c}} \mathrm{km}$ & $\mathrm{rms},{ }^{\mathrm{d}} \mathrm{s}$ \\
\hline 19 & Aqaba & 14 & 47 & 17.6 & 1.17 & 13.8 & 1.27 \\
\hline 20 & Gub & 10 & 1 & 9.8 & 1. & 14.9 & 1. \\
\hline 21 & Jiashi & 61 & 12 & 16.6 & 0.87 & 20.0 & 1.69 \\
\hline 22 & Spitak & 10 & 32 & 8.3 & 1.24 & 9.1 & 1.69 \\
\hline 23 & Tabas & 26 & 19 & 9.3 & 1.17 & 8.7 & 1.27 \\
\hline Overall & & 121 & 25 & 12.3 & 1.11 & 13.3 & 1.44 \\
\hline
\end{tabular}

${ }^{\mathrm{a}}$ Number of events with open azimuth $<180^{\circ}$ and $\geq 5$ stations.

${ }^{\mathrm{b}}$ Median number of stations.

${ }^{c}$ Average distance from estimated to GT location.

${ }^{\mathrm{d}} \mathrm{Rms}$ difference between observed and predicted travel times.

${ }^{\mathrm{e}}$ Total or average of cluster values.

largely control travel times. Finally, recent global models have been produced using Monte Carlo methods that generate ensembles of models from which uncertainties can be estimated.

[69] The principal disadvantage of global Earth models is that they contain little direct information about $v_{p}$ in the mantle, but it is the regional $P$ wave travel times that are most needed for location. For this reason, most recent efforts to improve regional location capabilities have been based either on compilations of regional empirical phase path anomalies to be used directly to construct empirical travel time "correction surfaces" or on regional $P$ wave tomography. An understanding of the difficulties of these approaches identifies the role of global 3D models in regional location.

[70] First, our experience is that information of GT10 quality or better results only after strenuous efforts and accrues only in isolated regions of the globe where reference events are available (e.g., from nuclear explosions or regions with outstanding local instrumentation). It is therefore not likely that empirically derived regional correction surfaces can be developed from GT10 databases in a general sense. It remains to be determined if empirical correction surfaces that derive from lower-quality locations will be able to perform as well as existing 3D Earth models, such as CUB2.0_TH, over large, diverse, and widely dispersed regions.

[71] Second, it is also much more difficult to provide constraints on $3 \mathrm{D}$ variations in $v_{p}$ in the uppermost mantle directly than to constrain $v_{s}$ variations, except in rare regions with exceptional station coverage and seismicity. $P_{n}$ tomography typically yields $2 \mathrm{D}$ surfaces of $v_{p}$ in the uppermost mantle and provides little or no information about the vertical velocity gradient needed to predict the turning point of regionally propagating phases. As discussed above, accurate determination of the turning point is crucial to determine regional travel times. In addition, as Ritzwoller et al. [2002b] show, the absolute level of $v_{p}$ in the uppermost mantle trades off with the station and event statics that are commonly introduced in $P_{n}$ tomography. $P_{n}$ tomography is therefore very good at diagnosing lateral variability in $v_{p}$ in the uppermost mantle, and $P_{n}$ tomographic maps have been shown by Ritzwoller et al. [2002b] to correlate well with uppermost mantle $v_{s}$ models of Eurasia [Villaseñor et al., 2001]. However, because absolute levels of $v_{p}$ are poorly determined, it remains unclear how to assimilate the results from $P_{n}$ tomography into 3D models. This is exacerbated by the inhomogeneity of the $P_{n}$ coverage and by the fact that 
(a) Explosions

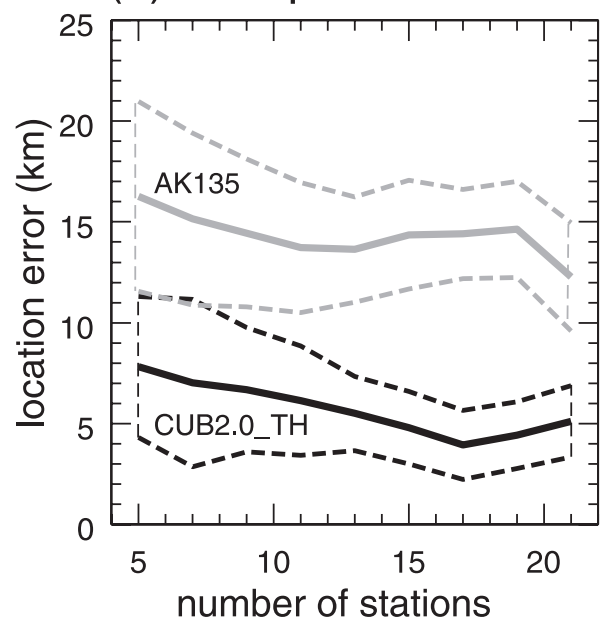

(c)

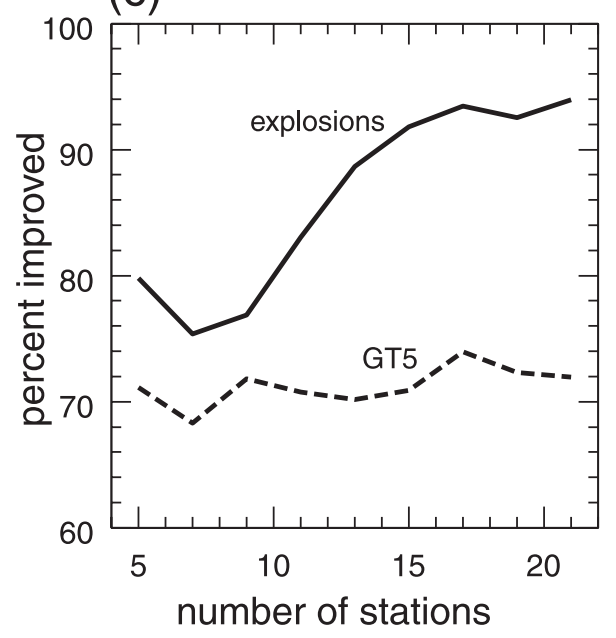

(b) GT5

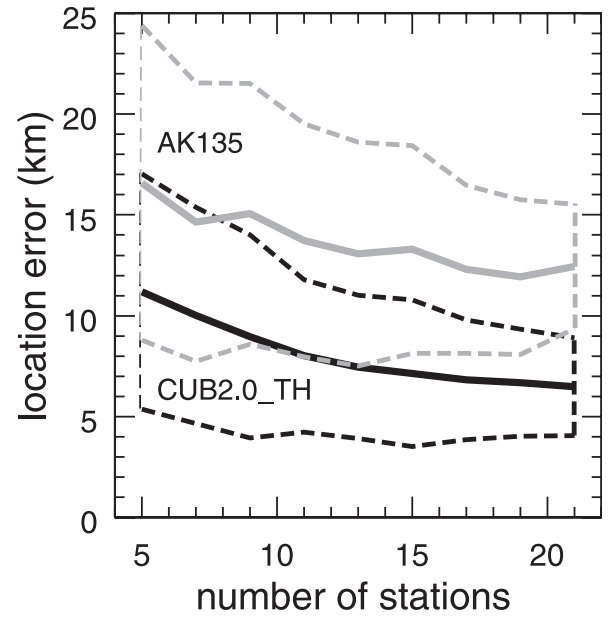

Figure 21. Location error for the $3 \mathrm{D}$ and $1 \mathrm{D}$ models, plotted as a function of the number of reporting stations, determined by randomly choosing subsets of the reported travel times in which open azimuth is constrained to be $<180^{\circ}$. (a and b) Averages (solid lines) and standard deviations (dashed lines) shown for explosions and GT5 earthquakes for CUB2.0_TH (black lines) and AK135 (shaded lines). (c) Percent of the events for which the location error is smaller using the 3D model than the $1 \mathrm{D}$ model for explosions (solid line) and GT5 earthquakes (dashed line).

$P_{n}$ is a very complicated phase, whose general characteristics exhibit substantial regional variation (e.g., number and location of triplications).

[72] The use of global 3D seismic models to improve regional location capabilities needs to be understood within the context of these difficulties that are inherent in acquiring information about regional $P$ wave travel times. The purpose of the 3D model is not to replace regional information where it exists but to complement and extend the information. We have shown here that relatively high-quality baseline information from existing 3D models now exists and provides the context into which more direct information about $P$ wave speeds can be introduced in the future. In addition, absolute locations from global 3D seismic models may also be useful in combination with relative event location methods that, ultimately, must be tied to absolute locations.

[73] The quality of $v_{s}$ models of the mantle has been improving rapidly over the past few years, and $v_{s}$ models are continuing to evolve. Future improvements in $v_{s}$ models, both through theoretical developments as well as through the assimilation of a variety of data that have hitherto not been used (e.g., heat flow (Shapiro and Ritzwoller, submitted manuscript, 2003); receiver functions [Julia et al., 2000]), will provide a natural path for advancements in regional location capabilities.

\subsection{Importance and Promise of the "Thermoelastic" $v_{s}$ to $v_{p}$ Conversion}

[74] The conversion of $v_{s}$ to $v_{p}$ has been a major stumbling block to adopting global 3D seismic models as part of both teleseismic and regional location methods. Recent advances in mineral physics have greatly improved the thermoelastic conversion of $v_{s}$ to $v_{p}$. Continued improvements in the theory (e.g., finite strain theory) as well as the development of ancillary information (e.g., information about the upper mantle composition) can be incorporated naturally into this conversion scheme. In addition, the conversion can be tuned regionally by varying the mantle 
composition and by optimizing the anelastic correction as well as other parameters in the conversion. To date, we have applied the $v_{s}$ to $v_{p}$ conversion directly from the mineral physics literature. Empirical phase path data sets, in particular, could be used to tune the conversion by optimizing certain parameters that are set in the conversion. These factors argue that the thermoelastic conversion from $v_{s}$ to $v_{p}$ provides a promising basis for future improvements in regional location capabilities based on 3D seismic models.

[75] Acknowledgments. We would like to thank Paul Richards and an anonymous reviewer for helpful, critical reviews. We gratefully acknowledge the staffs at the IRIS-DMC and the GEOFON and GEOSCOPE data centers for providing most of the waveform data on which the $3 \mathrm{D}$ model is based. We are also particularly grateful to Jeannot Trampert at Utrecht University and Michael Antolik, Goran Ekström, and Adam Dziewonski at Harvard University for providing phase speed measurements. The ray tracing software was written by Mikhail Barmin; Istvan Bondar, Joydeep Bhattacharyya, Vadim Levin, and Antonio Villaseñor provided useful feedback on its use. All maps were generated with the Generic Mapping Tools (GMT) data processing and display package [Wessel and Smith, 1991, 1995]. This work was supported by contracts DTRA01-99-C-0019, DTRA01-00-C-0013, and DTRA01-00-C-0032 from the Defense Threat Reduction Agency.

\section{References}

Antolik, M., G. Ekström, and A. M. Dziewonski, Global event location with full and sparse data sets using three-dimensional models of mantle $P$-wave velocity, Pure Appl. Geophys., 158, 291-317, 2001.

Barmin, M. P., A. L. Levshin, and M. H. Ritzwoller, A fast and reliable method for surface wave tomography, Pure Appl. Geophys., 158, $1351-$ 1375,2001

Bijwaard, H., W. Spakman, and E. R. Engdahl, Closing the gap between regional and global travel time tomography, J. Geophys. Res., 103, 30,055-30,078, 1998.

Boschi, L., and A. M. Dziewonski, High-and low-resolution images of the Earth's mantle: Implications of different approaches to tomographic modeling, J. Geophys. Res., 104, 25,567-25,594, 1999.

Červený, V., and I. Pšenćík, SEIS83-Numerical modeling of seismic wave fields in 2D laterally varying layered structures by the ray method, in Documentation of Earthquake Algorithms, Rep. SE-35, edited by E. R. Engdahl, pp. 36-40, Solid-Earth Geophys. Data Cent., Boulder, Colo., 1984.

Chen, Q.-F., and R. J. Willemann, Global test of seismic event locations using three-dimensional Earth models, Bull. Seismol. Soc. Am., 91, 1704-1716, 2001.

Duffy, T. S., and D. L. Anderson, Seismic velocities in mantle minerals and the mineralogy of the upper mantle, J. Geophys. Res., 94, 1895-1912, 1989.

Dziewonski, A. M., and D. L. Anderson, Preliminary reference Earth model, Phys. Earth Planet. Inter., 25, 297-356, 1981.

Ekström, G., and A. M. Dziewonski, The unique anisotropy of the Pacific upper mantle, Nature, 394, 168-172, 1998.

Ekström, G., J. Tromp, and E. W. F. Larson, Measurements and global models of surface wave propagation, J. Geophys. Res., 102, 81378157, 1997.

Engdahl, E. R., R. van der Hilst, and R. Buland, Global teleseismic earthquake relocation with improved travel time and procedures for depth determination, Bull. Seismol. Soc. Am., 88, 722-743, 1998.

Firbas, P., Location calibration based on 3D modelling: Steps towards the calibration of the global CTBT network, in Advances in Seismic Event Location, edited by C. H. Thurber and N. Rabinowitz, pp. 135-161, Kluwer Acad., Norwell, Mass., 2000.

Frémont, M. J., and S. D. Malone, High precision relative locations of earthquakes at Mount St., Helens, Washington, J. Geophys. Res., 92, 10,223-10,236, 1987.

Furlong, K. P., W. Spakman, and R. Wortel, Thermal structure of the continental lithosphere: Constraints from seismic tomography, Tectonophysics, 244, 107-117, 1995.

Geiger, L., Probability method for the determination of earthquake epicenters from the arrival time only, Bull. St. Louis Univ., 8, 60-71, 1912.

Goes, S., R. Govers, and P. Vacher, Shallow mantle temperatures under Europe from $P$ and $S$ wave tomography, J. Geophys. Res., 105, 11,153$11,169,2000$

Got, J.-L., J. Fréchet, and F. W. Klein, Deep fault plane geometry inferred from multiplet relative location beneath the south flank of Kilauea, J. Geophys. Res., 99, 15,375-15,386, 1994.
Graham, E. K., B. Yan, and K. P. Furlong, Lateral variations in upper mantle thermal structure inferred from three-dimensional seismic inversion models, Geophys. Res. Lett., 16, 449-452, 1989.

Jeffreys, H., and K. E. Bullen, Seismological Tables, Br. Assoc. for the Adv. of Sci., London, 1940.

Jordan, T. H., and K. A. Sverdrup, Teleseismic location techniques and their application to earthquake clusters in the south-central Pacific, Bull. Seismol. Soc. Am., 71, 1105-1130, 1981.

Julia, J., C. J. Ammon, R. B. Herrmann, and A. M. Correig, Joint inversion of receiver function and surface wave dispersion observations, Geophys. J. Int., 143, 99-112, 2000.

Kennett, B. L. N., and E. R. Engdahl, Travel times for global earthquake location and phase identification, Geophys. J. Int., 105, 429-465, 1991.

Kennett, B. L. N., E. R. Engdahl, and R. Buland, Constraints on seismic velocities in the Earth from travel times, Geophys. J. Int., 122, 108-124, 1995.

Levshin, A. L., M. H. Ritzwoller, and J. S. Resovsky, Source effects on surface wave group travel times and group velocity maps, Phys. Earth Planet. Inter., 115, 293-312, 1999.

McDonough, W. F., and R. L. Rudnick, Mineralogy and composition of the upper mantle, in Ultrahigh-Pressure Mineralogy: Physics and Chemistry of the Earth's Deep Interior, edited by R. J. Hemley, pp. 139-164 Mineral. Soc. of Am., Washington, D. C., 1998.

Minster, J. B., and D. L. Anderson, A model of dislocation-controlled rheology for the mantle, Philos. Trans. R. Soc. London, Ser. A, 299, 319-356, 1981 .

Mooney, W. D., G. Laske, and T. G. Masters, CRUST5.1: A global crustal model at $5^{\circ} \times 5^{\circ}$, J. Geophys. Res., 103, 727-748, 1998.

Murphy, J. R., I. O. Kitov, B. W. Barker, and D. D. Sultanov, Seismic source characteristics of Soviet peaceful nuclear explosions, Pure Appl. Geophys., 158, 2077-2101, 2001.

Myers, S. C., and C. A. Schultz, Improving sparse network seismic location with Bayesian Kriging and teleseismically constrainted calibration events, Bull. Seismol. Soc. A., 90, 199-211, 2000.

Myers, S. C., and C. A. Schultz, Statistical characterization of reference event accuracy (abstract), Seismol. Res. Lett., 72, 244, 2001.

Pavlis, G. L., Appraising relative earthquake location errors, Bull. Seismol. Soc. Am., 82, 836-859, 1992.

Piromallo, C., and A. Morelli, Improving seismic event location: An alternative to three-dimensional structural models, Pure Appl. Geophys., 158, 39-347, 2001.

Podvin, P., and I. Lecompte, Finite difference computation of travel times in very contrasted velocity models: A massively parallel approach and its associated tools, Geophys. J. Int., 105, 271-284, 1991.

Poupinet, G., W. L. Ellsworth, and J. Frechet, Monitoring velocity variations in the crust using doublets: An application to the Calaveras fault, California, J. Geophys. Res., 89, 5719-5731, 1984.

Ringdal, F., and B. L. N. Kennett (Eds.), Monitoring the Comprehensive Nuclear Test-Ban Treaty: Source Location, Pure Appl. Geophys., 158, 428 pp., 2001

Ritzwoller, M. H., and A. L. Levshin, Eurasian surface wave tomography: Group velocities, J. Geophys. Res., 103, 4839-4878, 1998.

Ritzwoller, M. H., N. M. Shapiro, M. P. Barmin, and A. L. Levshin, Global surface wave diffraction tomography, J. Geophys. Res., 107(B12), 2335, doi:10.1029/2002JB001777, 2002a.

Ritzwoller, M. H., M. P. Barmin, A. Villasenor, A. L. Levshin, and E. R. Engdahl, $P_{n}$ and $S_{n}$ tomography across Eurasia, Tectonophysics, 358, 39-55, 2002b.

Röhm, A. H. E., R. Snieder, S. Goes, and J. Trampert, Thermal structure of continental upper mantle inferred from S-wave velocity and surface heat flow, Earth Planet. Sci. Lett., 181, 395-407, 2000.

Schultz, C. A., S. C. Myers, J. Hipp, and C. J. Young, Nonstationary Bayesian kriging: A predictive technique to generate spatial corrections for seismic detection, location, and identification, Bull. Seismol. Soc. Am., $88,1275-1288,1998$.

Shapiro, N. M., and M. H. Ritzwoller, Monte Carlo inversion for a global shear velocity model of the crust and upper mantle, Geophys. J. Int., 151, $88-105,2002$.

Smith, G. P., and G. Ekström, Improving teleseismic event locations using a three-dimensional Earth model, Bull. Seismol. Soc. Am., 86, 788-796, 1996.

Sobolev, S. V., H. Zeyen, G. Stoll, F. Werling, R. Altherr, and K. Fuchs, Upper mantle temperatures from teleseismic tomography of French Massif Central including effects of composition, mineral reactions, anharmonicity, anelasticity and partial melt, Earth Planet. Sci. Lett., 157, 193-207, 1996.

Su, W., and A. M. Dziewonski, Simultaneous inversion for 3D variations in shear and bulk velocity in the mantle, Phys. Earth Planet. Inter, 100, $135-156,1997$. 
Su, W., R. L. Woodward, and A. M. Dziewonski, Degree 12 model of shear velocity heterogeneity in the mantle, J. Geophys. Res., 99, 6945-6980, 1994.

Thurber, C. H., and N. Rabinowitz (Eds.), Advances in Seismic Event Location, 266 pp., Kluwer Acad., Norwell, Mass., 2000.

Trampert, J., and J. Woodhouse, Global phase velocity maps of Love and Rayleigh waves between 40 and 150 seconds, Geophys. J. Int., 122, 675-690, 1995.

Trampert, J., P. Vacher, and N. Vlaar, Sensitivities of seismic velocities to temperature, pressure, and composition of the lower mantle, Phys. Earth Planet. Inter., 124, 255-267, 2001.

van der Hilst, R. D., S. Widiyantoro, and E. R. Engdahl, Evidence for deep mantle circulation from global tomography, Nature, 386, 578584, 1997.

van Wijk, J. W., R. Govers, and K. P. Furlong, Three-dimensional thermal modeling of the California upper mantle: A slab window vs. stalled slab, Earth Planet. Sci. Lett., 186, 175-186, 2001.

Villaseñor, A., M. H. Ritzwoller, A. L. Levshin, M. P. Barmin, E. R. Engdahl, W. Spakman, and J. Trampert, Shear velocity structure of cen- tral Eurasia from inversion of surface wave velocities, Phys. Earth Planet. Inter., 123, 169-184, 2001

Villaseñor, A., M. P. Barmin, M. H. Ritzwoller, and A. L. Levshin, Computation of regional travel times and station corrections from three-dimensional velocity models, Stud. Geophys. Geod., in press, 2003.

Waldhauser, F., and W. L. Ellsworth, A double-difference earthquake location algorithm: Method and application to the northern Hayward fault, California, Bull. Seismol. Soc. Am., 90, 1353-1368, 2000.

Wessel, P., and W. H. F. Smith, Free software helps map and display data, Eos Trans. $A G U, 72,441,445-446,1991$.

Wessel, P., and W. H. F. Smith, New version of the Generic Mapping Tools released, Eos Trans. $A G U, 76,329,1995$. [version 3.0]

E. A. Bergman, E. R. Engdahl, A. L. Levshin, M. H. Ritzwoller, and N. M. Shapiro, Center for Imaging the Earth's Interior, Department of Physics, University of Colorado at Boulder, Boulder, CO 80309-0390, USA. (bergmane@ciei.colorado.edu; engdahl@ciei.colorado.edu; levshin@ciei. colorado.edu; ritzwoller@ciei.colorado.edu; nshapiro@ciei.colorado.edu) 